\title{
Los ojos del Guadiana y del Gigüela: el resurgir de una masa de agua subterránea declarada "en riesgo"
}

\author{
J. del Pozo Tejado y M. Mejías Moreno \\ Instituto Geológico y Minero de España, Ríos Rosas 23, 28003 Madrid \\ j.delpozo@igme.es; m.mejias@igme.es
}

\begin{abstract}
RESUMEN
Los ojos del Guadiana y los ojos del Gigüela son un conjunto de manantiales que aportaban agua subterránea a sus respectivos cauces en condiciones naturales. Los del Guadiana constituyen el propio nacimiento del río, mientras que los del Gigüela surgían en el tramo final. A partir de la década de los 80 del pasado siglo la intensa explotación a la que fue sometido el Sistema Acuífero 23 generó un descenso del nivel piezométrico generalizado que, a su vez, provocó la desecación de dichos manantiales. Tras el periodo húmedo 20092013 se produjo una lenta recuperación de los acuíferos de las masas de agua subterráneas (MASb) centrales del Alto Guadiana, reflejado en un ascenso de niveles continuado hasta 2014-2015, pasando a continuación a registrarse un nuevo periodo de ligero descenso piezométrico. Los ojos del Guadiana resurgieron en enero de 2012, en pleno periodo de recuperación del acuífero, mientras que los ojos del Gigüela no presentaron agua hasta 4 años después, en diciembre de 2015, tras dos años hidrológicos secos y en periodo de descenso piezométrico incipiente. La evolución hidrogeológica registrada en el periodo diciembre 2009-febrero de 2016 da lugar al proceso de recuperación de los acuíferos de la Llanura Manchega, consecuencia del periodo húmedo mencionado. El desfase temporal en la presencia de agua entre ambos conjuntos de manantiales está relacionado con las características geológicas e hidrogeológicas del acuífero carbonatado Plioceno, concretamente con su morfología sedimentaria en el sector occidental. La evolución piezométrica de la Llanura Manchega en los últimos siete años describe el proceso de recuperación parcial de las MASb centrales, desde sus niveles más profundos hasta los más someros, en el sentido de avance natural del agua subterránea este-oeste.
\end{abstract}

Palabras clave: Hidrogeología, masa de agua subterránea en riesgo, ojos del Guadiana, ojos del Gigüela, Tablas de Daimiel.

\section{The Ojos del Guadiana and del Gigüela springs: the recovery of a groundwater body declared "at risk"}

\begin{abstract}
The "Ojos del Guadiana" and the "Ojos del Gigüela" are a set of springs that provide groundwater to the respective channels under natural conditions. The first are the source of the Guadiana river, whilst the second ones are located in the final stretch of the river. From the 1980s the intense exploitation of Aquifer System 23 generated a decrease in the groundwater level, which in turn caused these springs to dry up. After the wet period of 2009-2013 there was a slow recovery of the aquifers in the Upper Guadiana, reflected in a rise in the levels, which continued throughout 2014-2015, this then changed to register a new period of piezometric decline. The "Ojos del Guadiana" reappeared in January 2012 during the period of recovery of the aquifer, whilst water in the "Ojos del Gigüela" appeared four years later, in December 2015, after two dry hydrological years and the beginning of a period of piezometric decline. Hydrogeological developments in the period of December 2009 to February 2016 resulted in the recovery process of the aquifers in the Mancha Plain due to this wet period. The time lag in the presence of water in the two sets of springs is related to the geological and hydrogeological characteristics of calcareous Pliocene aquifer, specifically with its morphology in the western sector. The piezometric evolution of the Mancha Plain in the last 7 years describes the process of partial recovery of the Upper Guadiana Central Sector, from its deepest to its shallowest levels in the sense of the direction of the natural progression of the groundwater from east to west.
\end{abstract}

Keywords: hydrogeology, ground water body at risk, Ojos del Guadiana, Ojos del Gigüela, Tablas de Daimiel. 
del Pozo Tejado, J. y Mejías Moreno, M., 2017. Los Ojos del Guadiana y del Gigüela: ... Boletín Geológico y Minero, 128 (4): 885-911

\section{ABRIDGED ENGLISH VERSION}

\section{Introduction}

The study area includes the surface extension with geological and hydrogeological influence of the "Ojos del Guadiana" and "Ojos del Gigüela" springs. The limit of the study area describes a polygon with vertex in the Tablas de Daimiel National Park (TDNP) and the villages of Villarrubia de los Ojos, Villarta de San Juan, Manzanares and Torralba de Calatrava (Ciudad Real, Castilla-La Mancha, Spain) (Fig. 1).

The Mancha Plain is characterized by an irregular rainfall regime in a hydrological year. The sequence of a few years with similar precipitation conditions constitutes long periods with humid or dry tendencies.

The last wet sequence was in the 2009 to 2013 period, when the precipitation was intense, especially in the winters of 2009-2010 and 2012-2013. The more recent hydrological years of 2013/14, 2014/15 and 2015/16 were classified as dry years (Fig. 2).

The mean annual discharge in the "Ojos del Guadiana" springs (before 1980) was around $100 \mathrm{hm}^{3} / \mathrm{year}$. There is no historical register for the "Ojos del Gigüela" springs. The statistical analysis of the natural flow in the Guadiana river shows an annual mean discharge of about $66 \mathrm{hm}^{3} / y e a r$ from subterranean resources and $24 \mathrm{hm}^{3}$ year from the Azuer river (Table 1).

The study area is located in the Mancha Plain Domain (east-west direction), bounded on the west with the Hesperian Massif Domain, to the north with Sierra de Altomira, to the northeast with the Iberian Range and to the south with the Campo de Montiel Domain (Fig. 3). The Mancha Plain is a morphostructural depression filled with Mesozoic and Cenozoic deposits that overlies by discordance on the Paleozoic basement(shales and quartzites.)

The western sector of the Mancha Plain is composed by Cenozoic sediments exclusively, except for the eastern third band that includes Triassic evaporitic deposits (clays and gypsum of Keuper facies). By a discordant contact, the bottom of the Cenozoic series starts with a level of gravel, sand and clay sediments (low Pliocene). A calcareous facies were deposited overlaying the detritic facies, composed of limestones, marls and clays and gypsum marls (upper Pliocene). The transition Pliocene-Pleistocene is composed of calcareous crusts. The Quaternary deposits are gravels in colluvial and fan deposits, sands and clays in alluvial levels that include peat deposits and evaporitic levels, usually in the flood plain of the principal rivers. The calcareous levels show solution structures such as uvalas and sinkholes in the surface, with sinkhole clay deposits at the bottom of the structures (Fig. 3).

The thickness of the filled up basin decreases towards the E-W extremes. The isobath map of the bottom of the calcareous unit (Figs. 4 and 5) shows the relationship between the morphology of the bottom of the calcareous unit and the top of the basement. Local geology is managed by this relationship (Fig. 6).

The study area is located over the ground water body GWB 041007 Mancha Occidental I. The conceptual hydrogeological model of this aquifer shows that the groundwater flow comes from the higher peripheral sectors, towards the central depression conformed by the GWB Mancha Occidental I, Mancha Occidental II and Rus-Valdelobos (Figure 7). The water table contours (February, 2016) indicate a E-W subterranean flux direction, similar to a natural condition stage.

\section{Results and Discussion}

The recent piezometric evolution of the study area shows an evident influence of the climatologic events (2009-2013 wet period) with the upward tendency in the last 6 years (Fig. 8 a). Detailed analysis of this evolution indicates a quite different piezometric behaviour in the eastern and western areas of the "Ojos del Guadiana" springs (Table 2).

The piezometric contour map (February 2016) differentiates 3 sectors in the Guadiana river valley (Fig. 9). An influent stream in the oriental sector; effluent on the left margin and an influent stream on the right side of the Ojos del Guadiana-Azuer river segment; and effluent behaviour from the Azuer incorporation towards TDNP. This situation shows the actual flood conditions in the Guadiana river. The Gigüela river has an effluent regime in the study area.

The "Ojos del Guadiana" and the "Ojos del Gigüela" springs are classified as plain springs, and the hydrogeological interpretation of the origin is related with the natural drainage points of the Llanura Manchega aquifer (H.U. 23). The water table is on the surface, and the springs correspond with natural (or anthropic) depressions that show water in the bottom when the piezometric level is above a certain altitude (Fig. 11).

Piezometric evolution in the central sector of upper Guadiana (Fig. 10) shows a progressive approximation to the "natural conditions" in the Mancha Plain, where the original direction of subterranean flow (east to west) has been recovered during this period.

The morphology of the Pliocene carbonate unit manages the hydrogeological evolution in the occidental 
del Pozo Tejado, J. y Mejías Moreno, M., 2017. Los Ojos del Guadiana y del Gigüela: ... Boletín Geológico y Minero, 128 (4): $885-911$

sector of the Llanura Manchega aquifer. The aquifer's spatial and depth limitations in the subterranean output sector are the decisive factors (Figs. 12 and 13). Interpretation requires a starting stage of minimum piezometric levels (summer 2009).

The wet period of 2009-2013 provided a huge recharge volume. We have to distinguish two types of recharge: the surface recharge, which comes from the rainfall infiltration and the river connection and has an immediate and moderate effect on the water levels; and the subterranean recharge, which comes from the GWB Mancha Occidental II and has a delayed but more efficient effect on the piezometric rise.

The piezometric evolution of the last 7 years in the study area describes the effect of the filling of the aquifer, conditioned by the sedimentary thresholds and depocenters in the output aquifer sector where the piezometric level is forced to rise due to aquifer limitation (Figs. 14 and 15). The depocenters of Daimiel and Las Tablas improve the delayed effect of water presence in the "Ojos del Gigüela" compared to the "Ojos del Guadiana".

\section{Introducción}

Los ojos del Guadiana y del Gigüela se sitúan en la cuenca alta del río Guadiana (CAG), caracterizada por una estrecha interrelación entre las aguas superficiales y las subterráneas. La conexión hidráulica entre los acuíferos y los ríos tiene carácter efluente o influente de forma variable, dependiendo de la zona considerada, la secuencia climática o incluso de la época del año en la que nos encontremos.

Se entiende por ojos un conjunto de manantiales (ojos en el caso del Guadiana) que, en condiciones naturales, se alimentaban del drenaje del agua subterránea del Sistema Acuífero 23, actualmente subdividido en varias masas de agua subterránea (MASb). Por su parte los ojos del Gigüela (ojuelos según la denominación local), eran manantiales situados en la Ilanura de inundación del río homónimo, que aportaban agua subterránea al cauce superficial proveniente del drenaje del mismo acuífero.

Históricamente el río Guadiana nacía en los denominados Ojos del Guadiana. El agua subterránea en la Llanura Manchega se desplaza de este a oeste, desde sus zonas de recarga más orientales hasta sus zonas de drenaje a través de Los ojos del Guadiana, los ojos del Gigüela, Las Tablas de Daimiel y los ríos que los conectan. Esta situación será considerada en este artículo como "condiciones naturales", escenario que comienza a modificarse a partir de la implantación del plan de desecación de humedales del año 1956 (BOE de 18 de julio) sobre "Saneamiento y colonización de los terrenos pantanosos que se extienden inmediatos a las márgenes de los ríos Guadiana, Cigüela, Záncara y afluentes de estos dos últimos en las provincias de Ciudad Real, Toledo y Cuenca". Pero no es hasta finales de la década de los 70 del pasado siglo cuando los regadíos agrícolas intensivos generan un descenso piezométrico que modifica progresivamente la dinámica regional del flujo subterráneo, hasta que se produce la desecación de los Ojos del
Guadiana a partir del año 1983, circunstancia en la que se alteran las condiciones naturales del acuífero y se pasa a una situación hidrogeológica modificada por la acción antrópica.

Los Ojos del Guadiana permanecieron secos hasta enero de 2012. En este año, como consecuencia del intenso periodo húmedo 2009-2013, se detecta la presencia de discretos encharcamientos sin continuidad en las depresiones topográficas más pronunciadas de la llanura de inundación. En diciembre de 2015 se advierte la primera presencia de agua en los ojos del río Gigüela, igualmente en forma de encharcamientos aislados.

El aspecto novedoso que se pretende mostrar en este trabajo no es tanto un planteamiento hidrogeológico nuevo, o la aplicación de una técnica de análisis diferente a las ya utilizadas en los numerosos trabajos previos existentes en la zona. Se trata más bien de la interpretación de una situación hidrológica que no se había dado nunca desde que existe registro piezométrico. Los ojos del Guadiana y del Gigüela eran puntos de drenaje natural del Sistema Acuífero 23, de forma permanente, hasta el año 1983. A partir de este año ambos conjuntos de manantiales se secan durante un periodo de más de 30 años. Se ha producido la recuperación de la surgencia de agua en los ojos del Guadiana y del Gigüela por primera vez desde que se hace un seguimiento sistemático del acuífero.

El hecho Ilamativo que lleva a centrar la atención sobre la surgencia de agua en estos puntos, y a preguntarse sobre el porqué de sus circunstancias, es el desfase temporal existente entre la surgencia de los ojos del Guadiana y los del Gigüela (4 años de diferencia). Además, la surgencia de agua en los ojos del Gigüela tiene lugar en una situación hidrogeológica "en retroceso", tras tres años secos que hacen que los niveles de todos los piezómetros de la zona presenten una tendencia descendente.

En el presente artículo se establece una hipótesis de funcionamiento hidrológico local que, a tenor de 
del Pozo Tejado, J. y Mejías Moreno, M., 2017. Los Ojos del Guadiana y del Gigüela: ... Boletín Geológico y Minero, 128 (4): $885-911$

cómo y cuándo se ha producido el proceso de recuperación piezométrica, da explicación teórica a esta singularidad. En adelante, el seguimiento hidrogeológico se debería enfocar en la búsqueda de datos que corroboren la hipótesis planteada, a la par que se deberían planificar nuevos trabajos de investigación específicos.

\section{Objetivos}

Mediante la actualización del conocimiento de la geología e hidrología del entorno de los ojos del Guadiana y del Gigüela, se pretenden esclarecer las circunstancias que han llevado al resurgimiento de manantiales que han permanecido secos desde principios de la década de los años ochenta del pasado siglo. Además, se pretende averiguar las circunstancias que han dado lugar al desfase temporal entre la presencia de agua en los ojos del Guadiana con respecto a los del Gigüela.

La masa de agua subterránea en la que se ubican ambos conjuntos de manantiales (MASb Mancha Occidental I) fue declarada "en riesgo de no alcanzar el buen estado cuantitativo y químico" según se recoge en el BOE-B-2014-45025 de 22 de diciembre de 2014. En el presente artículo se analiza la situación hidrológica de la MASb únicamente en su aspecto cuantitativo.

En el artículo 26 del Plan Hidrológico de la cuenca del Guadiana (RD 1/2016 de 8 de enero) se define la posibilidad de no alcanzar el buen estado cuantitativo de la MASb Mancha Occidental I así como su volumen de recurso disponible. Según se recoge en la Disposición Transitoria Única de la Ley 11/2012 de 19 de diciembre, hasta que no se apruebe el Plan de Actuación de la MASb se seguirá aplicando lo estipulado en el Plan de Ordenación de Extracciones.

En los últimos años se está produciendo un aparente retorno a las condiciones hidrológicas del régimen natural, anteriores al año 1983. La recuperación se refiere a la dinámica de flujo subterráneo del acuífero, no así a los volúmenes de drenaje que todavía distan mucho de alcanzar los valores anteriores al año 1980.

El acercamiento a la situación descrita se hace, por un lado, desde una perspectiva hidrogeológica, a partir de la piezometría del entorno de los ríos Guadiana y Gigüela a fecha de febrero de 2016, momento en que se encuentran activas las "nuevas" surgencias de agua. Por otro lado, desde una perspectiva histórica, se analizan los condicionantes climatológicos y la evolución piezométrica que han tenido influencia en el escenario hidrológico de las últimas décadas.
Los resultados hidrogeológicos obtenidos por ambas vías se confrontan con la información geológica e hidrogeológica disponible, con objeto de aunar estos desde diferentes perspectivas, en busca de una aproximación realista a la hidrogeología de los ojos del Guadiana y del Gigüela y, por extensión, a la de la MASb 041.007 Mancha Occidental I.

\section{Delimitación y localización de la zona de estudio}

La zona de interés se centra en el área de confluencia de los ríos Guadiana y Gigüela y en el entorno del Parque Nacional de Las Tablas de Daimiel (PNTD). Los ojos se sitúan en la llanura de inundación y cauce de ambos ríos, a escasos kilómetros aguas arriba del Parque Nacional. Entre ambos puntos de surgencia hay una distancia de 7 kilómetros aproximadamente (Figura 1).

Con respecto a la delimitación de la zona de estudio, se han considerado los siguientes límites con significado hidrogeológico: al oeste, el límite del Parque Nacional de Las Tablas de Daimiel, en el que el cauce del río Guadiana constituye el punto más bajo de drenaje subterráneo que puede tener influencia en los ojos del Guadiana y del Gigüela; al noroeste y norte el límite se hace coincidir con el cauce del río Gigüela, dado que representa el nivel de base de la descarga subterránea procedente de la Llanura Manchega; al sur y suroeste la divisoria de aguas subterráneas entre el río Azuer y el arroyo Pellejero; por último, al este, la divisoria se establece en el límite oriental de la MASb Mancha Occidental I con la Mancha Occidental II.

El área de estudio pertenece en su totalidad a la provincia de Ciudad Real, próxima a su límite norte con la provincia de Toledo (comunidad autónoma de Castilla-La Mancha). Se ubica en la Demarcación Hidrográfica del río Guadiana, concretamente en la cuenca alta del rio Guadiana (CAG), entendida esta como el sector oriental de la Demarcación. Los ríos principales son el Guadiana, desde su nacimiento en Los ojos del Guadiana hasta su entrada en el Parque Nacional de las Tablas de Daimiel; el río Gigüela, tributario del primero por su margen derecha y cuya confluencia se produce dentro de los límites del Parque Nacional, y el río Azuer, tributario del Guadiana por su margen izquierda.

Morfológicamente se sitúa en el sector noroccidental de la Llanura Manchega, ocupando el corredor central de la cuenca alta del Guadiana. La llanura está limitada por los relieves de Sierra de Altomira y los Montes de Toledo al norte, y por los de Campo de Montiel y la subcuenca de Campo de Calatrava, al sur y oeste respectivamente. 


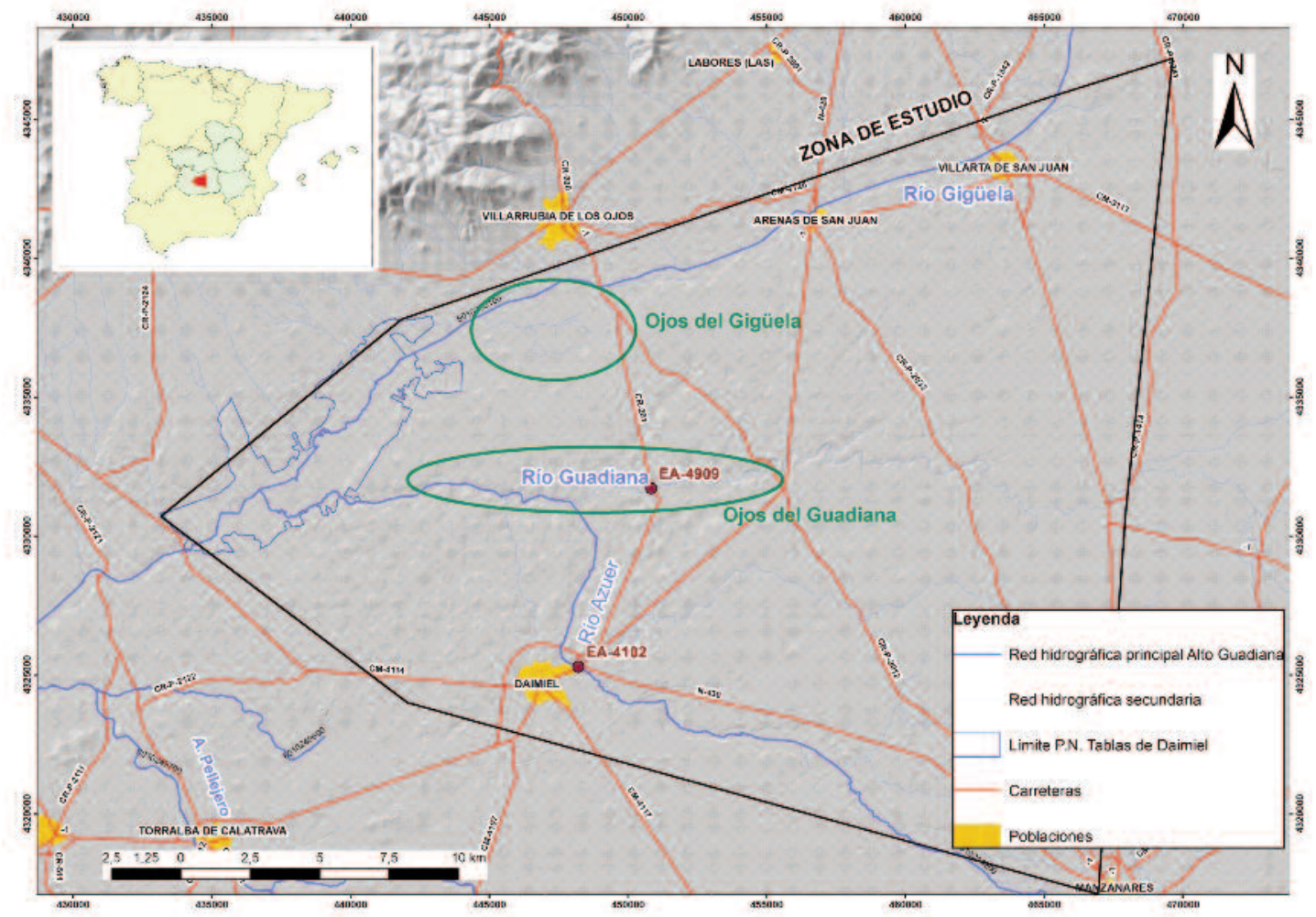

Figura 1. Localización geográfica y delimitación del área de estudio.

Figure 1. Geographical location and limits of the study area.

\section{Climatología}

El registro de datos de la estación meteorológica 4112U, Las Tablas de Daimiel, representativa de la zona de estudio, presenta una precipitación media anual es de $418,8 \mathrm{~mm}$, en un periodo de 54 años. Varían entre un valor mínimo de $208,8 \mathrm{~mm}$ (año hidrológico 1995/96) y un máximo de $706,6 \mathrm{~mm}$ (año hidrológico 1961/62). En general, las precipitaciones tienen una distribución irregular, alternándose series prolongadas de años secos y medios con series húmedas de menor duración temporal (del Pozo y Mejías, 2015).

Para el objeto del presente artículo, se centra el foco del análisis sobre los últimos años de la serie, concretamente en el periodo que abarca desde el año 2009 hasta febrero de 2016. Las intensas precipitaciones ocurridas durante el periodo 2009-2013 (años hidrológicos húmedos 2009/10, 2010/11 y 2012/13), son la principal causa de la tendencia piezométrica ascendente de los últimos años. A partir de 2014 se suceden tres años hidrológicos secos con escasez de precipitaciones que siguen la misma línea (Figura 2).

\section{Descripción y análisis hidrológico de los ojos del Guadiana y del Gigüela}

\section{Los ojos del Guadiana}

Los ojos del Guadiana son un conjunto de manantiales que, en régimen natural, antes del intenso aprovechamiento de los recursos hídricos subterráneos del Sistema Acuífero 23, salpicaban el área del nacimiento del río constituyendo pequeñas depresiones topográficas en las que surgía el agua subterránea; la unión de los regatos que nacían en cada "ojo" daba lugar a escorrentía superficial, formando el tramo más alto del cauce. Este continuaba discurriendo hacia su confluencia con el Gigüela y, en los 15 kilómetros que recorría hasta su encuentro, en las márgenes y en el propio cauce iban surgiendo "manaderos" que aportaban sus aguas al río, constituyendo un singular entramado de aguas superficiales y subterráneas. En régimen natural, el caudal del río Guadiana en este tramo es variable en función del periodo climatológico. Los valores obtenidos de algunas referencias bibliográficas indican que aguas arri- 


\section{Las Tablas de Daimiel}

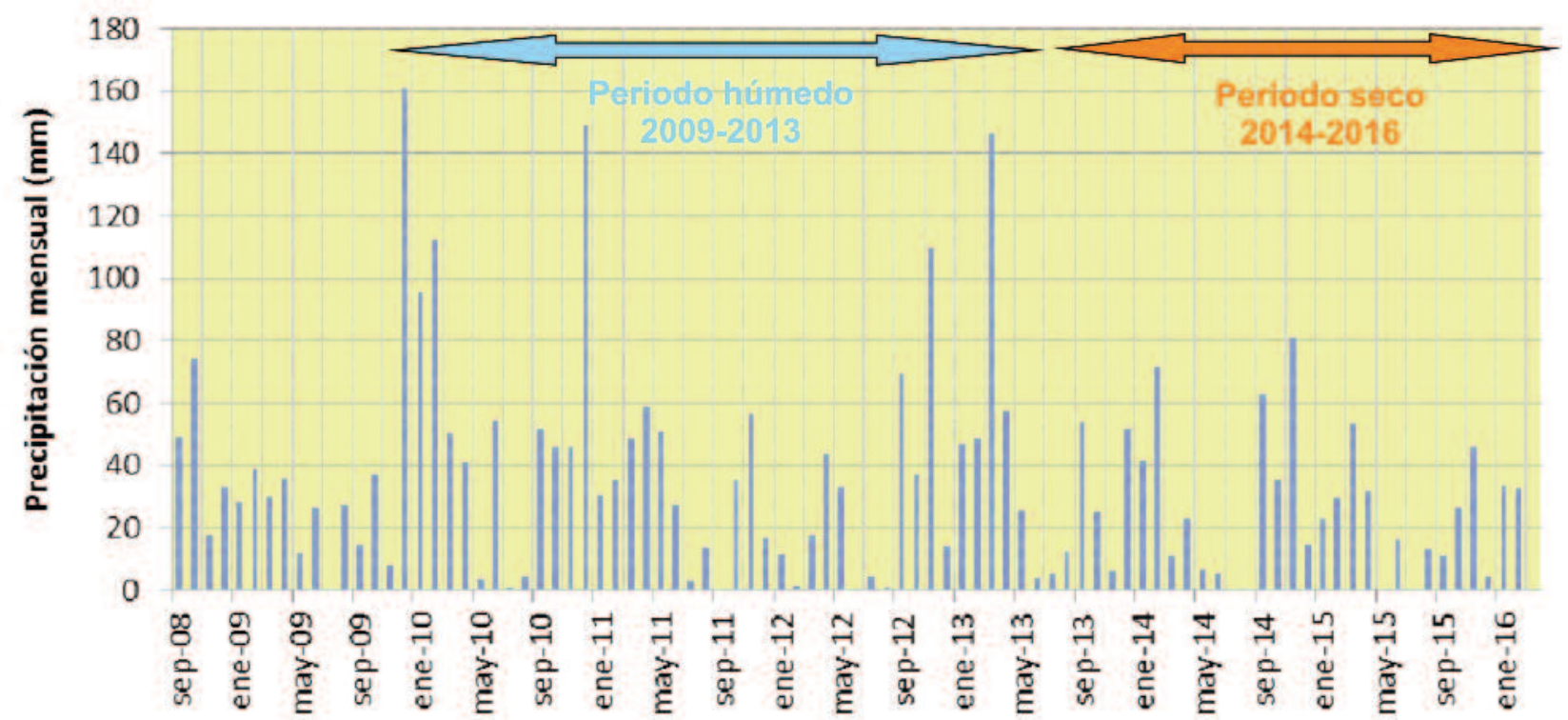

Figura 2. Precipitación mensual registrada en la estación de las Tablas de Daimiel, en el periodo septiembre de 2008 - febrero de 2016 (fuente de datos AEMET y Parque Nacional de las Tablas de Daimiel).

Figure 2. Monthly precipitation Sept. 2008- Feb.2016 in Las Tablas de Daimiel station.

ba de la confluencia con el río Azuer, en el periodo 1915-1932, era de 61 hm³/año (Álvarez Cobelas, 2001) o de 72 hm³/año para el mismo periodo, según García Rodríguez, 1996. En Hernández Pacheco, 1932 se recoge una aportación de $68 \mathrm{hm}^{3} /$ año en el periodo 1925-

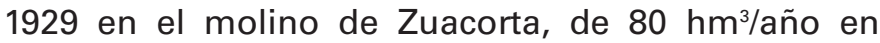
ITGE, 1989 en el tramo comprendido entre Los Ojos

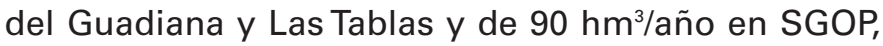
1979 para ese mismo tramo. Como valor medio, García Rodríguez, 1996, estima un aporte de Los Ojos

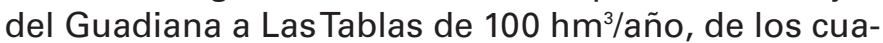
les $70 \mathrm{hm}^{3} / a n ̃ o$ eran aportados por el propio río Guadiana, $20 \mathrm{hm}^{3} / a$ ño por el río Azuer, y $10 \mathrm{hm}^{3} /$ año por manantiales a lo largo del cauce.

El análisis de los caudales mensuales históricos realizado por los autores de este artículo (Tabla 1) presenta los siguientes valores para la serie histórica registrada en las estaciones de aforo EA-4102 Río Azuer en Daimiel y EA-4909 Río Guadiana en Zuacorta, cuya posición se refleja en la figura 1. En la determinación del caudal medio anual de cada estación de aforo se han contabilizado los años hidrológicos que cuentan con un mínimo de 9 valores mensuales con dato a lo largo del año.

Se obtiene así un valor medio anual de caudal, para el tramo del río Guadiana desde su nacimiento hasta la estación de aforo de Zuacorta, de 65,91 hm³/año para la serie temporal 1914/15-1940/41 calcu- lados sobre 25 años con datos, de un total de 27 años de registro.

En el caso del río Azuer, el valor medio de caudal en la estación de aforo 4102-Río Azuer en Daimiel, es de $24,02 \mathrm{hm}^{3}$ /año para la serie 1948/49-2011/12 calculados sobre 16 años con datos, de un total de 56 años de registro.

El valor de caudal máximo registrado en la estación 4909-Río Guadiana es de 98,7 hm³/año en el año hidrológico 1933/34. Para la estación 4102-Río Azuer, el valor máximo registrado es de $67,4 \mathrm{hm}^{3} /$ año para el año $1963 / 64$. Destacar que en el año $2009 / 10$ para un total de 8 meses con dato fue de $45 \mathrm{hm}^{3} / a$ ño.

A partir de enero de 2012, como se ha citado anteriormente, volvieron a surgir algunos de los ojos del Guadiana, produciendo escorrentía superficial y llegando a alcanzar un aporte máximo de aguas subterráneas al río en el tramo comprendido entre el molino de La Máquina y el Nuevo, inmediatamente después de la confluencia con el río Azuer, estimado en unos $11 \mathrm{hm}^{3}$ en el año 2014. Aguas arriba de este punto, en el río Guadiana no se ha producido escorrentía que se pudiera medir, quedando al aporte de agua subterránea limitado a encharcamientos del terreno. Este volumen puntual de descarga es un 78 $\%$ menor que el caudal drenado de forma permanente en condiciones naturales. No solo la magnitud es significativamente menor como para pensar en una 
del Pozo Tejado, J. y Mejías Moreno, M., 2017. Los Ojos del Guadiana y del Gigüela: ... Boletín Geológico y Minero, 128 (4): 885-911

\begin{tabular}{|l|c|c|}
\hline & \multicolumn{2}{|c|}{ ESTACIONES DE AFORO } \\
\hline & 4102 Río Azuer & 4909 Río Guadiana en Zuacorta \\
\hline Serie histórica & $1948 / 49-2011 / 12$ & $1914 / 15-1940 / 41$ \\
\hline Años hidrológicos contabilizados & 16 & 25 \\
\hline $\mathbf{Q}_{\text {máximo }}\left(\mathbf{h m}^{3}\right.$ /año) & $67,4(1963 / 64)$ & $98,7(1933 / 34)$ \\
\hline $\mathbf{Q}_{\text {medio }}\left(\mathbf{h m}^{3}\right.$ /año) & 24,02 & 65,91 \\
\hline
\end{tabular}

Tabla 1. Caudales en las estaciones EA-4102-Río Azuer y EA-4909-Río Guadiana en Zuacorta.

Table 1. Discharge rate in the gauging stations EA-4102-Azuer river, and EA-4909- Guadiana river in Zuacorta.

recuperación total del sistema hidrogeológico, sino que, además, el caudal máximo se produce durante un breve periodo de tiempo, pasando a continuación a reducirse progresivamente este volumen hasta hacerse nulo en el verano de 2016.

\section{Los ojos y ojuelos del Gigüela}

Los ojos del Gigüela se describen también como un conjunto de manantiales y surgencias situados al suroeste de la localidad de Villarrubia de los Ojos (Ciudad Real). En esta zona el río Gigüela conforma una amplia llanura de inundación que, en estado natural, se encontraba permanentemente inundada por efecto del desbordamiento de las aguas superficiales en toda su amplitud, y por aportes de agua subterránea a través de los ojos u ojuelos (Jerez, 2011).

El funcionamiento hidrodinámico de los ojuelos es similar al de los ojos del Guadiana. Se trata de depresiones en el terreno, de morfología tendente a circular, en cuyo fondo se intercepta la superficie freática. El agua de estos puntos era reconducida mediante regueros naturales y acequias artificiales, para ser aprovechada en el riego de huertas y cultivos, confluyendo finalmente en el río Gigüela.

Como consecuencia del encauzamiento del río Gigüela dictado por la ley de 1956 mencionada anteriormente, se produce la desecación de gran parte de la llanura de inundación al impedirse el desbordamiento del río. Se incrementó así la superficie de aprovechamiento agrícola, regada a partir de la excavación de una densa red de acequias artificiales que aprovechaban el agua subterránea drenada por los ojuelos. El periodo de intensa explotación del acuífero que tiene lugar a partir de los primeros años de la década de los 80 del siglo anterior supuso la desecación total de los manantiales que aún persistían. No se tiene constancia de la fecha exacta de desecación de los ojuelos ni tampoco se han encontrado referencias bibliográficas relativas a los caudales circulantes por la mencionada red de regueros y acequias. La reaparición de agua se fecha en diciembre de 2015.

\section{Marco geológico}

\section{Geología regional}

La zona de estudio se localiza en el sector noroeste de la región natural de La Mancha, concretamente en el tercio occidental del dominio geológico de la Llanura Manchega (Figura 3). Este dominio queda delimitado al oeste por el Macizo Hespérico (zona Centro (bérica), al norte por el dominio de la Sierra de Altomira, al este por la rama Castellana de la Cordillera lbérica $y$, al sur, por la denominada Cobertera Tabular del Campo de Montiel (AlonsoGavilán et al., 2004; Mejías, 2014).

La Llanura Manchega está conformada por una fosa o surco tectónico, de dirección este-oeste, rellena de materiales mesozoicos y cenozoicos. El mayor espesor se alcanza en el sector central y disminuye hacia sus márgenes (IGME, 2010). La reducción de espesor en el sector occidental se produce por desmantelamiento erosivo de los bloques más elevados. El acuñamiento progresivo en sentido occidental hace desaparecer, por este orden, a los materiales cretácicos, jurásicos y triásicos (Figura 3). En el sector más occidental de la Llanura Manchega, los materiales de relleno de la fosa son de edad exclusivamente cenozoica, y se disponen directamente sobre el zócalo paleozoico compuesto fundamentalmente por cuarcitas y pizarras.

En el extremo occidental el zócalo paleozoico asciende progresivamente hasta cerrar la cuenca sedimentaria, aflorando en el sector occidental de la Llanura Manchega (figura 4). La serie neógena que colmata la cuenca reduce progresivamente su potencia en este sentido, hasta desparecer las series carbonatada y detrítica en este orden.

En superficie, los materiales cenozoicos que col- 

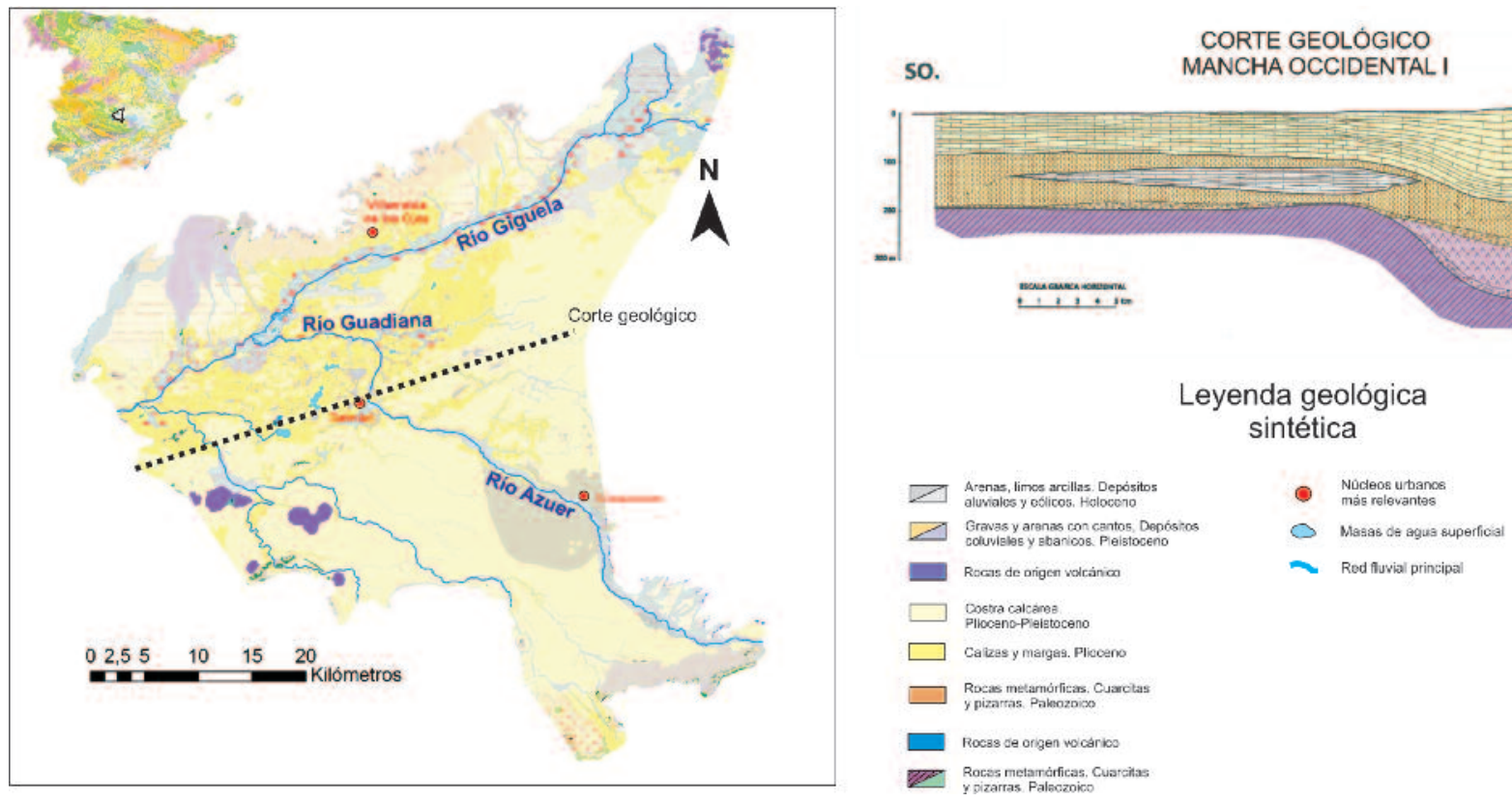

Figura 3. Marco geológico regional del Dominio de la Llanura Manchega (modificado de Mejías, 2014).

Figure 3. Location of the study area according to geologicaldomains (modified from Mejías, 2014).

matan la cuenca dan lugar a una extensa planicie constituida a partir de la serie sedimentaria continental y caracteriza la morfología plana de la Llanura Manchega.

\section{Geología local}

La serie estratigráfica presente en la zona de estudio (IGME, 1988) está compuesta por, de muro a techo, el zócalo de la serie sedimentaria neógena compuesto por cuarcitas y pizarras de Paleozoico en el tercio central y occidental mientras que, en el oriental, sobre la serie paleozoica se encuentra la serie de materiales evaporíticos triásicos; a continuación se dispone, de forma discordante, la serie neógena integrada por una serie detrítica en su base, compuesta de conglomerados, arenas, limos y arcillas distribuidos de forma granodecreciente en sentido distal desde el área fuente (márgenes de la fosa tectónica); a continuación se dispone una serie carbonatada, heterogéneamente distribuida, con frecuentes cambios laterales de facies, compuesta por calizas y margas principalmente, con niveles evaporíticos en la base y varios niveles de costra calcárea Pliocena que coronan la serie; por último, los sedimentos cuaternarios se disponen tapizando la serie carbonatada, distribuidos en función de su origen fluvial, kárstico o en forma de mantos eólicos (Figura 3).

\section{Tectónica}

La Tectónica alpina y postalpina incluye varios eventos tectónicos de importancia clave en el funcionamiento de la dinámica hidrogeológica de la Llanura Manchega.

Durante la deformación neógena se reactivan antiguas fracturas del zócalo paleozoico, de dirección E-O y NE-SO y las submeridionales $\mathrm{N} 160^{\circ}$ a $180^{\circ}$ (Pérez González, 1981). En el Neógeno superior se suceden diferentes fases distensivas, que dan lugar a la estructura del basamento en forma de bloques levantados y hundidos (estructuras pop up y pop down) que a efectos del relleno sedimentario posterior origina los depocentros de Villarta de San Juan, Daimiel y de Las Tablas durante el Mioceno superior (Figura 4). En una segunda etapa distensiva, se amplía la cuenca de sedimentación a toda la Llanura Manchega en el límite Plioceno inferior- Plioceno superior (IGME, 1988).

Durante el Plioceno superior se produce el basculamiento hacia el oeste de la cuenca de la Llanura Manchega, dando salida en este sentido a los cauces fluviales que hasta entonces tenían un carácter endorreico. En el Pleistoceno se produce el encajamiento de la red fluvial, de escaso desarrollo en el caso de la Llanura Manchega.

Tomando como base la morfología de las unidades sedimentarias deducibles de los mapas de isobatas del techo del zócalo paleozoico y de las isobatas 

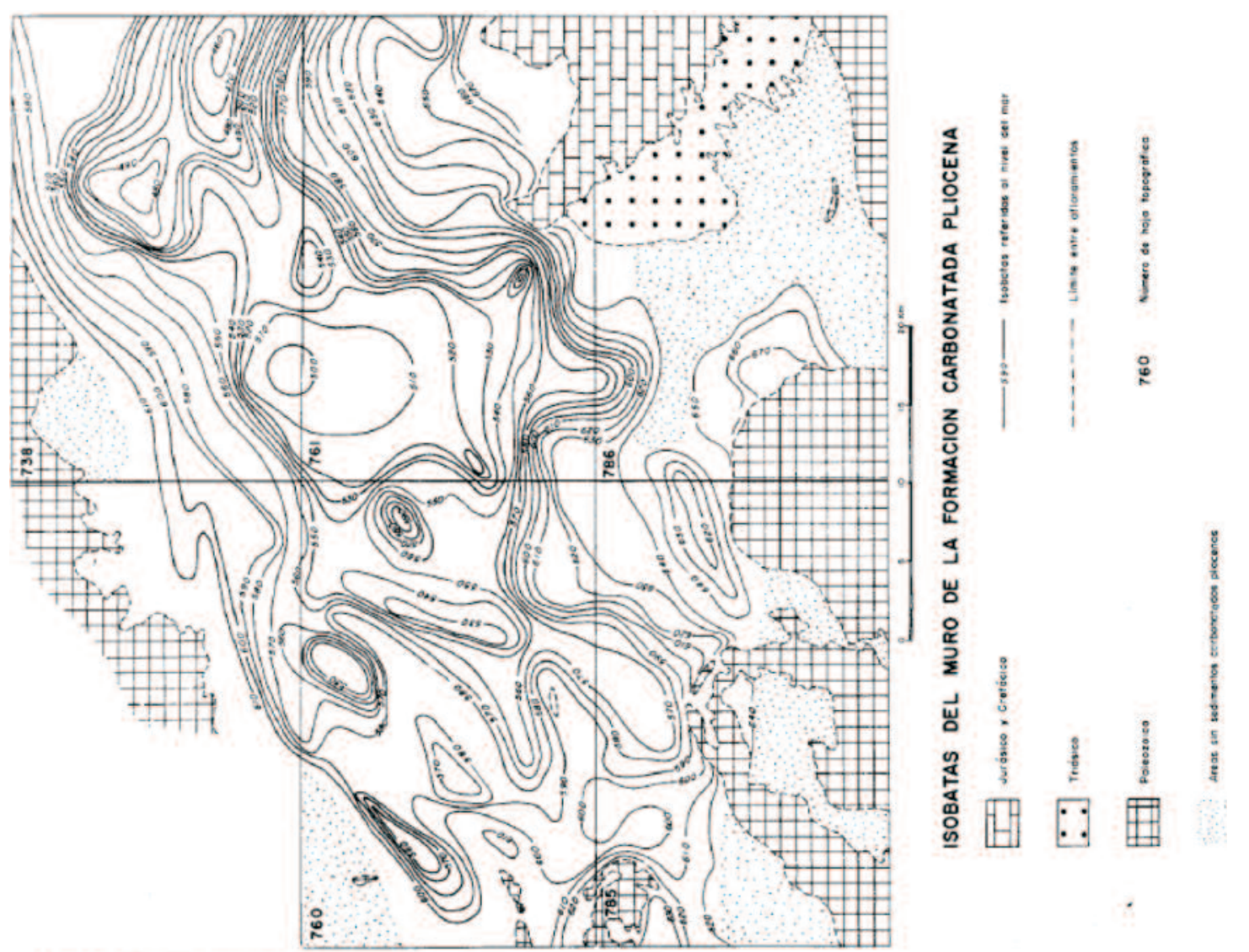

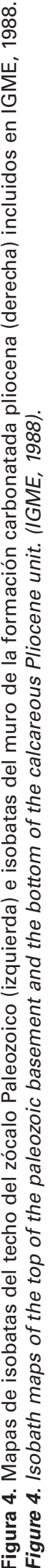
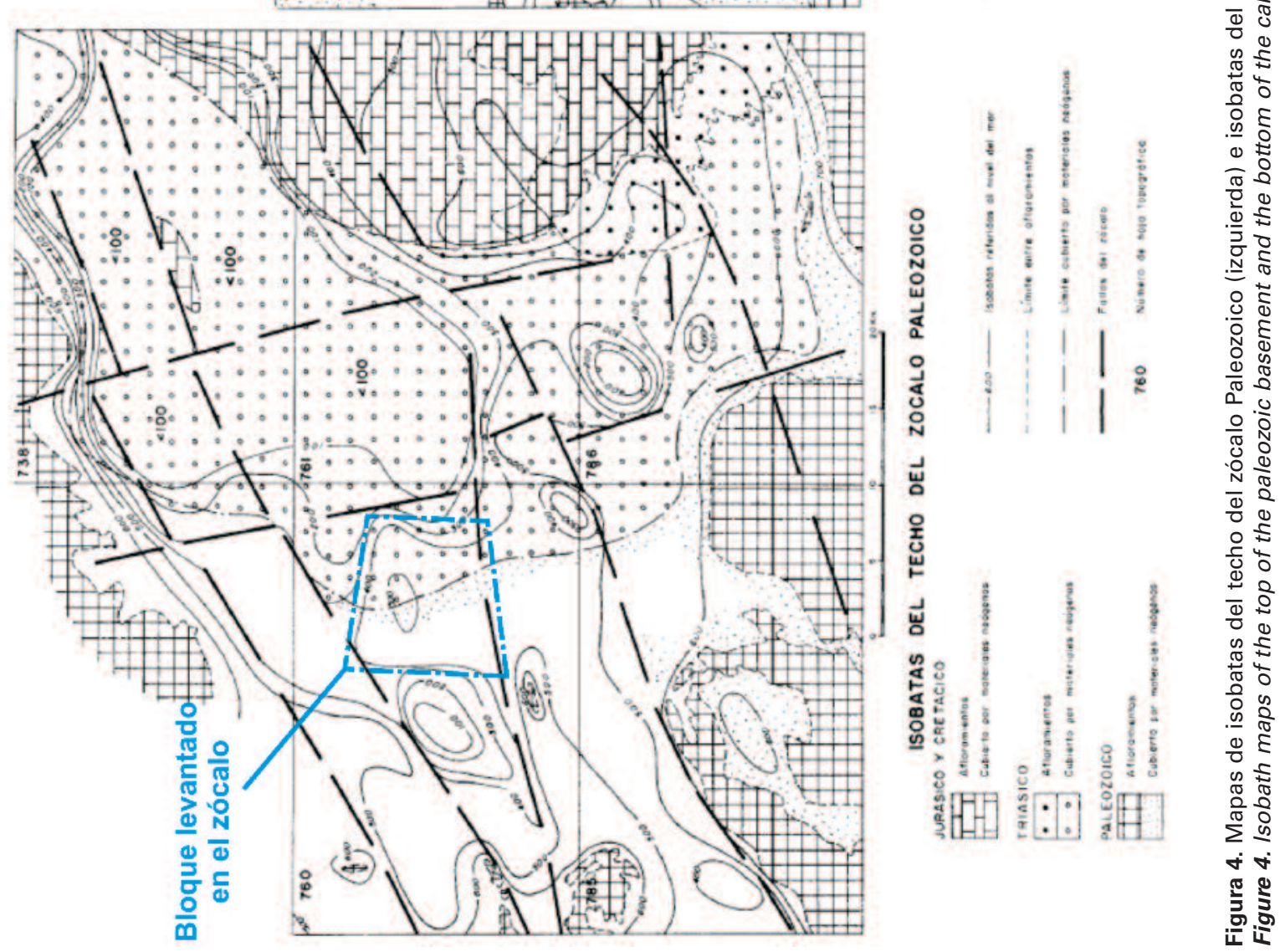


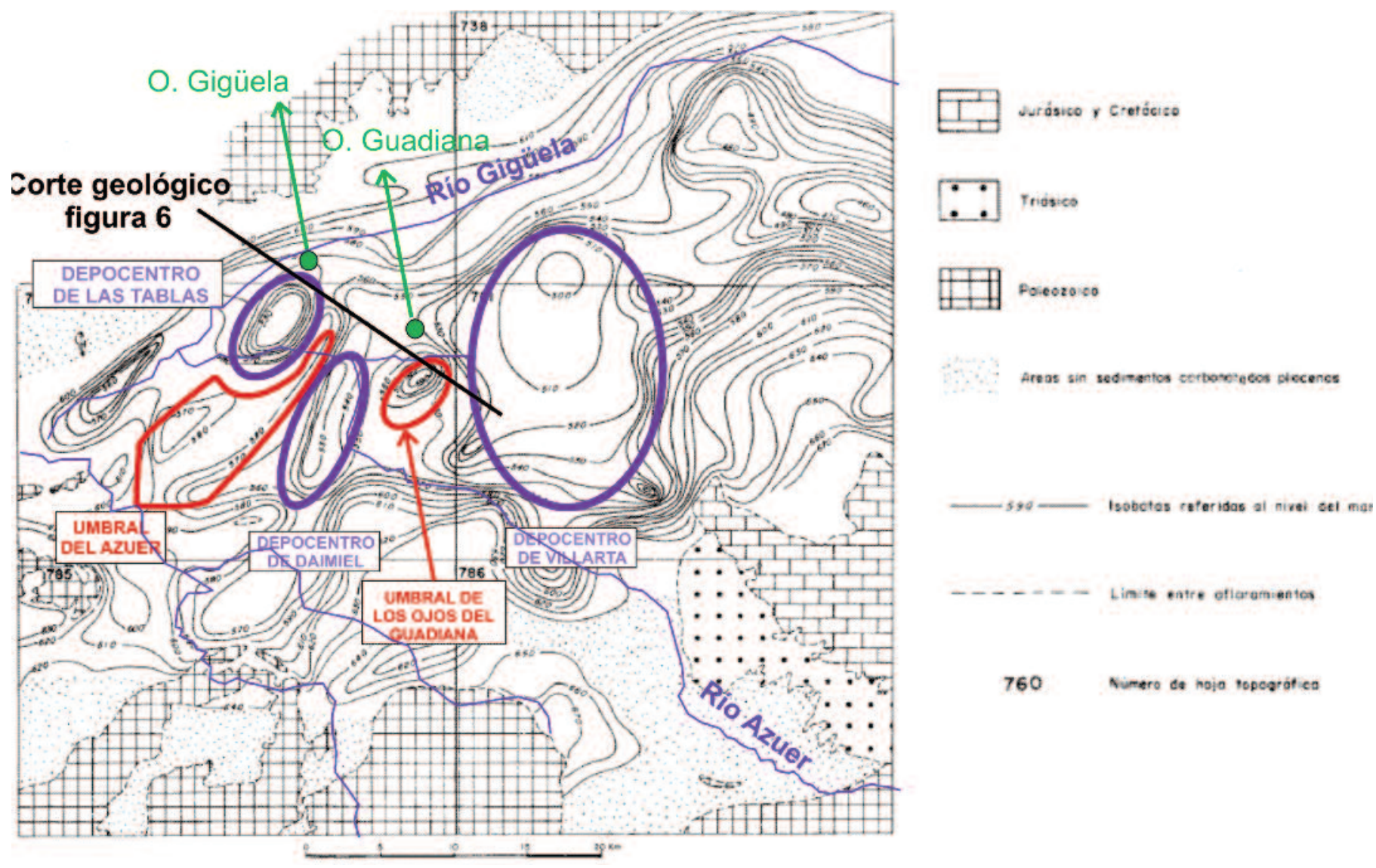

Figura 5. Identificación de umbrales y depocentros sedimentarios en la serie carbonatada Pliocena referidas en este artículo (modificado de IGME, 1988).

Figure 5. Sedimentary thresholds and depocenters in the calcareous Pliocene unit mentioned in the article (modified from IGME, 1988).

del muro de la unidad litoestratigráfica carbonatada pliocena (IGME, 1988; Antón, 1975; CGS-INTECSA, 1975), se puede detallar la arquitectura y morfología de las unidades sedimentarias neógenas (detrítica y carbonatada) en la zona de estudio.

Se identifican varios sectores de la unidad carbonatada pliocena en los que su morfología se ve condicionada por la topografía de la base de la unidad (Figura 5). Así, en los depocentros de Las Tablas, de Villarta de San Juan, y de Daimiel la potencia de la serie carbonatada aumenta considerablemente hasta alcanzar espesores de más de 200 metros en el de Villarta (Antón, 1975). En los umbrales sedimentarios se produce una reducción de la potencia de la unidad carbonatada (Figura 6).

El umbral sedimentario de Los Ojos del Guadiana, situado inmediatamente al sur del paraje de Los Ojos del Guadiana, se origina como consecuencia de la sobreelevación de las facies arcillosas de la unidad terciaria detrítica, cuya deposición se produjo sobre un domo o bloque levantado en el basamento (figura
6). En el perfil geológico de detalle, elaborado a partir de la información litológica de sondeos de las bases de datos del IGME y de la CHG, se refleja la disposición del umbral en relación a la posición de Los ojos del Guadiana. Existe un segundo umbral (umbral del Azuer) que supone una reducción de potencia de la unidad carbonatada pliocena interpuesta entre los depocentros de Daimiel y de Las Tablas.

\section{Marco hidrogeológico}

\section{Hidrología superficial}

Los ríos de la Llanura Manchega siguen la dirección que mayoritariamente presentan sus directrices tectónicas dominantes. Tienen una pendiente escasa, cauces amplios y extensas llanuras de inundación. Las aguas subterráneas tienen una influencia decisiva en su caudal, favorecida por la escasa pendiente y la proximidad del nivel piezométrico a la superficie. Los 


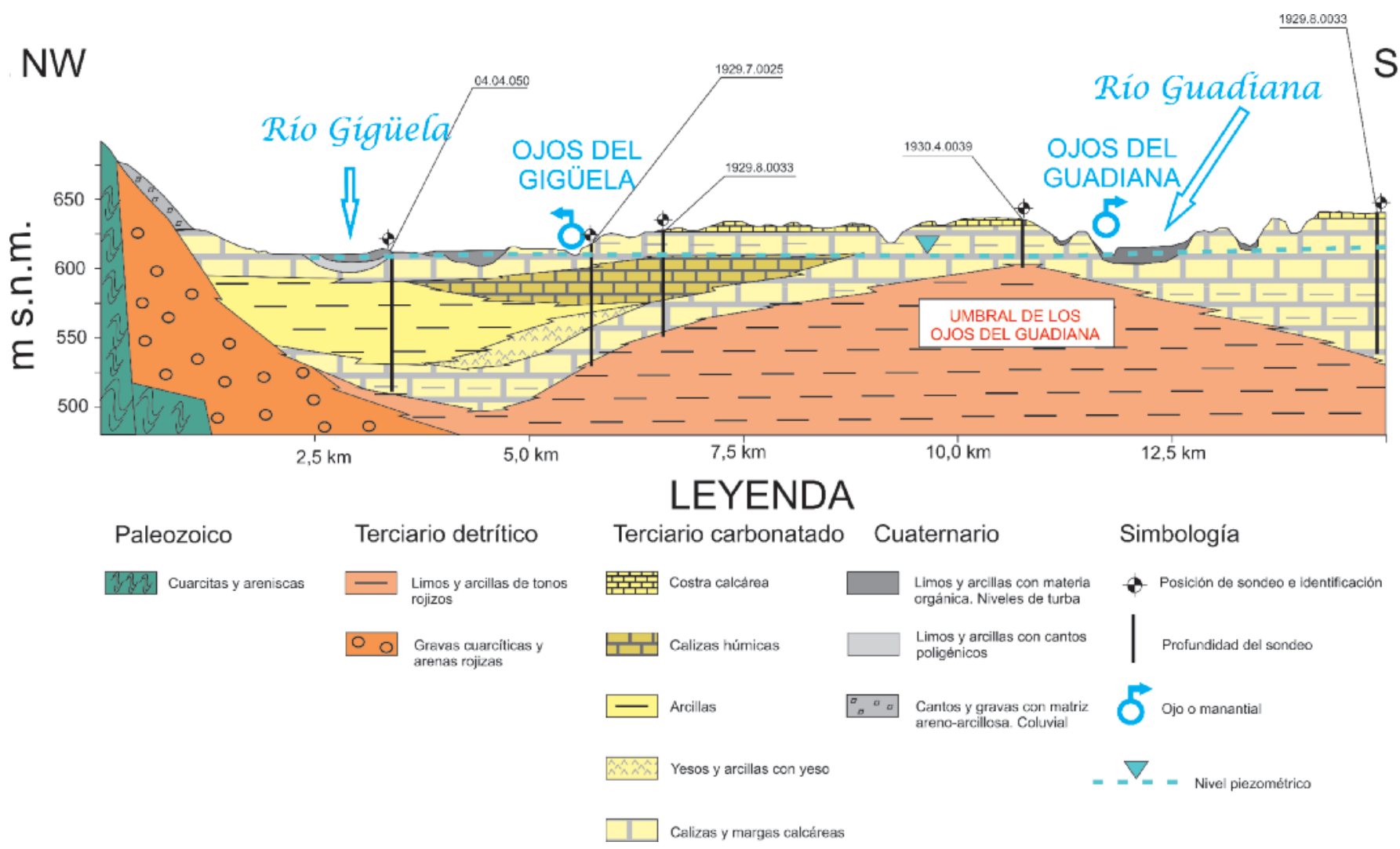

Figura 6. Perfil geológico-hidrogeológico del entorno de Los Ojos del Guadiana y del Gigüela (la posición del perfil se refleja en la figura 5). Nótese el umbral sedimentario conformado por el nivel de limos y arcillas de la unidad terciaria detrítica.

Figure 6. Geological-hydrogeological cross section in the "Ojos del Guadiana-Ojos del Gigüela" area. The position of the cross section is reflected in Figure5. See the sedimentary threshold of "Los Ojos del Guadiana".

ríos son largos en su mayoría, con tramos de carácter efluente o influente variables en función de la época del año, las secuencias climatológicas y el aprovechamiento de las aguas subterráneas.

Los cursos de agua más destacados son el río Guadiana y su afluente por la margen izquierda el río Azuer, y el río Gigüela, afluente del río Guadiana por su margen derecha y cuya confluencia se produce en el interior de los límites del Parque Nacional de las Tablas de Daimiel.

\section{Hidrogeología}

La zona de estudio se localiza en el ámbito de la masa de agua subterránea (MASb) 041.007 Mancha Occidental I (R.D. 1/2016 de 8 de enero) en su sector septentrional, próxima al límite con los relieves paleozoicos del Dominio del Macizo Hespérico (Zona Centroibérica).

Pertenece al sector hidrogeológico de la cuenca alta del Guadiana (CAG) y, junto a las MASb 041.006
Mancha Occidental II, y 041.005 Rus-Valdelobos, constituyen el sector central de la CAG (Figura 7).

La CAG presenta una dinámica hidrogeológica que ha de ser entendida en su conjunto. El aspecto más destacable en este sentido es la circulación de agua superficial y subterránea desde las áreas de recarga periféricas, más elevadas topográficamente, hacia el sector central $y$, dentro de este sector, en sentido este-oeste hacia su extremo occidental. Hacia el este se describe una divisoria de aguas subterráneas, de posición variable (López Gutiérrez et al., 2013), que delimita hidrogeológicamente La Mancha Occidental de La Mancha Oriental, perteneciente esta última a la demarcación hidrográfica del río Júcar (Figura 7).

La circulación de agua subterránea en el conjunto de la CAG es posible debido a la interconexión hidráulica entre las MASb que la integran. El sector central constituye la vía de drenaje de agua superficial y subterránea de toda la cuenca alta del Guadiana hacia las zonas más deprimidas topográficamente, esto es el cauce del Guadiana a la altura de las Tablas de Daimiel y el embalse del Vicario, al oeste. 
Las entradas de agua en el conjunto de las tres MASb se producen por infiltración de agua de lluvia, por recarga a partir los ríos y por transferencia lateral subterránea, principalmente desde las MASb Sierra de Altomira al norte, y Campo de Montiel al sur (Martínez Cortina et al, 2011; Mejías et al, 2012). En el sector central de la CAG existe continuidad hidrogeológica entre las tres MASb, produciéndose transferencia de flujo subterráneo desde la MASb RusValdelobos hacia la Mancha Occidental II y de esta hacia la MASb Mancha Occidental I. Las principales salidas de agua subterránea en el conjunto de la CAG se producen por drenaje hacia ríos y manantiales, por evaporación en las zonas de humedal y por extracciones por bombeo.

En la figura 8 se representa el mapa de isopiezas del periodo de aguas altas de 2016, elaborado a partir de las medidas de marzo de 2016 tomadas en la red de observación piezométrica de la CHG y del IGME. Se mantiene una dinámica hidrogeológica similar a las condiciones del "estado natural", en las que el flujo subterráneo circula en sentido este-oeste. El restablecimiento parcial de este esquema de flujo se inició en año 2012, manteniéndose hasta el actual 2016.

\section{Aprovechamiento de las aguas subterráneas}

El volumen anual de extracciones en la CAG siempre ha resultado un dato controvertido y de difícil medición. Algunas estimaciones del IGME presentan valores en torno a $60 \mathrm{hm}^{3} / a n ̃ o$ durante la década de los años 50 del siglo pasado y de unos $180 \mathrm{hm}^{3} /$ año a mediados de los años setenta. A fínales de los ochen-

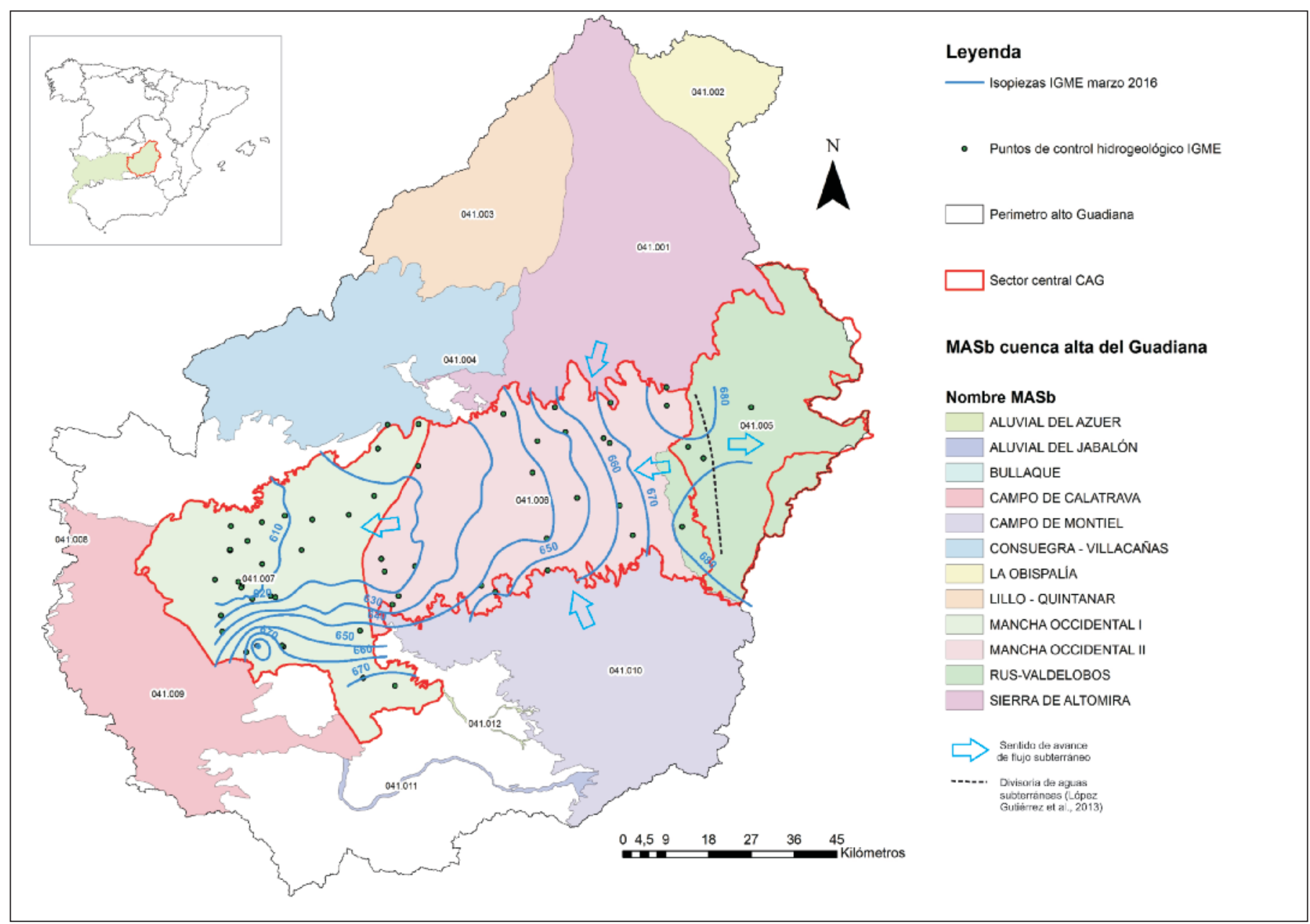

Figura 7. MASb de la cuenca alta del Guadiana y dinámica hidrogeológica del conjunto. Isopiezas de marzo de 2016 en el sector central de la CAG.

Figure 7. GWB of the Upper Guadiana and hydrogeological model. Piezometric contour map February 2016. 
del Pozo Tejado, J. y Mejías Moreno, M., 2017. Los Ojos del Guadiana y del Gigüela: ... Boletín Geológico y Minero, 128 (4): $885-911$

ta y principio de los noventa se alcanzó la extracción máxima, que superó los $500 \mathrm{hm}^{3} / a n ̃ o ~ y$, al final del último periodo seco en 2009, se estaban extrayendo unos $400 \mathrm{hm}^{3} /$ año (Martínez-Cortina et. al, 2011). Esto ha supuesto una importante variación en el volumen de agua almacenado en el acuífero con respecto al año de referencia 1980, en el que todavía se mantenía el esquema natural de flujo subterráneo, estableciéndose un vaciado del volumen de agua almacenado, para las tres MASb centrales de la CAG, de unos 3.750 $\mathrm{hm}^{3}$ a finales de 1996, unos $2.000 \mathrm{hm}^{3}$ a finales de 1999, después del periodo húmedo 1995/98; se incrementa de nuevo a unos $3.000 \mathrm{hm}^{3}$ en 2009 y, en 2014, después del periodo húmedo $2009 / 13$, se reduce a tan solo $350 \mathrm{hm}^{3}$ de vaciado. En el año 2016 el volumen vaciado es de aproximadamente $700 \mathrm{hm}^{3}$.

Ante esta situación de sobreexplotación, la Junta de Gobierno de la Confederación Hidrográfica del Guadiana declara sobreexplotado en 1987, de manera provisional, un polígono que comprende los límites del Sistema Acuífero $23 \mathrm{y}$, el mismo órgano, el 15 de diciembre de 1994, aprueba el Plan de Ordenación de las Extracciones y declara la sobreexplotación provisional como definitiva. A partir de ese momento, cada año debe aprobarse, también por la Junta de Gobierno de la CHG, el Régimen Anual de Extracciones que supone el límite máximo autorizado de extracción de aguas subterráneas para cada año natural.

De 1987 a 1995 no se establece un límite máximo de extracciones, sino una serie de limitaciones y condiciones en función, básicamente, de la superficie a regar, el volumen autorizado y si el predio se situaba en la zona de protección del Parque Nacional de Las Tablas de Daimiel. De 1992 a 2002 se establece un volumen máximo de extracciones para la unidad hidrogeológica Mancha Occidental de 200 hmªño, $30 \mathrm{hm}^{3}$ para abastecimiento y los $170 \mathrm{hm}^{3}$ restantes para uso agrícola. En 2003 se aprueban 260 hmªño, $30 \mathrm{hm}^{3}$ y $230 \mathrm{hm}^{3}$ respectivamente; en 2004, 230 $\mathrm{hm}^{3} / \mathrm{año}$; en 2005, $200 \mathrm{hm}^{3}$; en 2006, 213,4 $\mathrm{hm}^{3}$ y de 2007 a 2017 se aprueban $230 \mathrm{hm}^{3} / a$ ño, $30 \mathrm{hm}^{3}$ para abastecimiento y $170 \mathrm{hm}^{3}$ para uso agrícola.

\section{Análisis piezométrico de los ojos del Guadiana y del Gigüela}

\section{Evolución piezométrica reciente del acuífero Plioceno}

Los antecedentes de las circunstancias hidrológicas que han dado lugar a la situación actual pueden analizarse tomando como referencia el periodo 20082016, que abarca la secuencia húmeda 2009-2013 y los posteriores años secos hasta el actual 2016. Para el seguimiento de la evolución piezométrica de este periodo se han representado los piezómetros con seguimiento mensual pertenecientes a las redes de observación de la CHG y el IGME.

La evolución de los piezómetros de observación, representativa de la situación de los acuíferos a nivel regional, refleja una tendencia común de ascensos y descensos piezométricos ligados a la pluviometría (Figura 8 a). La piezometría refleja fielmente las secuencias húmedas y secas, de forma que los ascensos y descensos se correlacionan directamente con las precipitaciones.

En los gráficos de evolución piezométrica cabe diferenciar las oscilaciones anuales, que se producen como respuesta a la variación estacional de un mismo año hidrológico y cuya magnitud depende, básicamente, de la intensidad de las precipitaciones, de aquellas variaciones que describen una tendencia ascendente o descendente "de fondo", consecuencia de las secuencias climatológicas de duración plurianual (Figura 8 a). Según esta tendencia general, a partir de 2009 se produce un notable ascenso piezométrico en el periodo 2010-2011 que rompe con la tendencia descendente previa a diciembre de 2009. A partir de enero de enero de 2012 el ascenso piezométrico se mantiene constante pero con una pendiente significativamente menor. La fecha en que se alcanza el máximo piezométrico relativo es ligeramente diferente en función del piezómetro y la zona, pasando por último a una fase de estabilización y ligero descenso piezométrico. A fecha de febrero de 2016 todos los piezómetros han alcanzado su máximo piezométrico y se encuentran en proceso de ligero descenso.

Más allá de la tendencia piezométrica general de los puntos de observación, se observan ciertos aspectos que ayudan a entender la dinámica hidrogeológica de este sector.

Por un lado, los piezómetros analizados muestran que la superficie piezométrica se encuentra progresivamente más próxima a la superficie en sentido esteoeste, y nos aproximamos a la zona de descarga del acuífero, en el entorno del paraje de Los Ojos del Guadiana y de las Tablas de Daimiel. Consecuentemente, las aguas subterráneas tendrán una influencia mayor en los cursos de agua superficiales, y en la geomorfología del terreno. Este efecto geomorfológico queda evidenciado por el incremento significativo de estructuras de disolución (dolinas y uvalas) al oeste del umbral de Los Ojos del Guadiana (sector occidental, figura 8 b).

Por otro lado, la amplitud de la variación piezométrica interanual, y también la absoluta, es de menor magnitud en sentido este-oeste. Este aspecto se traduce en una mayor estabilidad piezométrica en el 


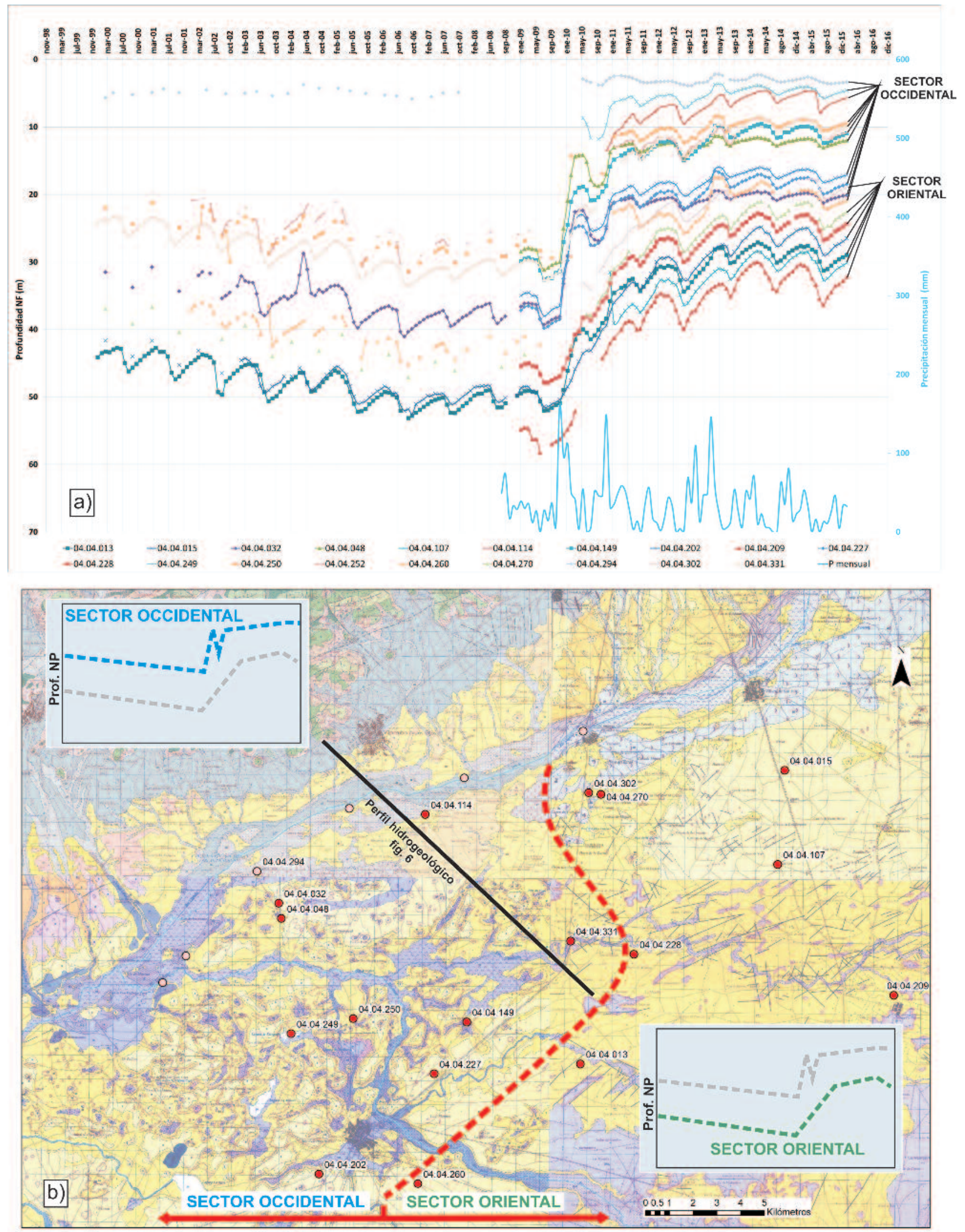

Figura 8. a) Gráfico de evolución piezométrica (febrero de 2016). b) Posición de puntos de control (fuente IGME y CHG). Figure 8. a): Piezometric evolution diagram (Feb. 2016). b) Piezometer positions in the study area. 
del Pozo Tejado, J. y Mejías Moreno, M., 2017. Los Ojos del Guadiana y del Gigüela: ... Boletín Geológico y Minero, 128 (4): 885-911

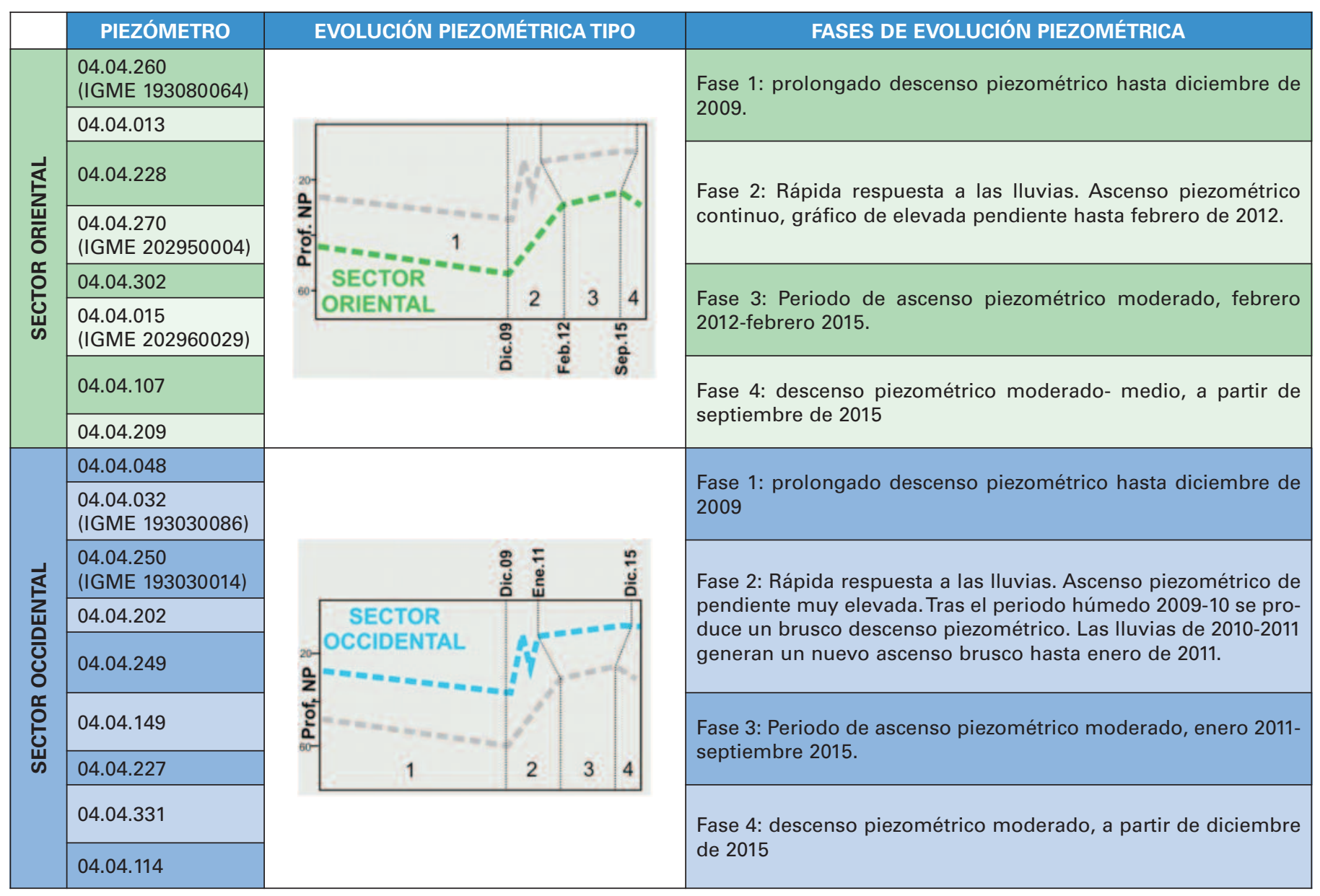

Tabla 2. Agrupación de piezómetros en función de su evolución piezométrica en el periodo diciembre 1999 - febrero 2016.

Table 2. Piezometer groups according the piezometric behaviour in the period between December 1999 and February 2016.

sector occidental (figura 8 b). Este comportamiento es clave en la formación y preservación de humedales y ecosistemas ligados a las aguas subterráneas como lo son los ojos del Guadiana y los del Gigüela y, a la postre, las Tablas de Daimiel.

Las gráficas de evolución piezométrica reflejan la evolución climatológica de la zona, como ya se ha dicho. Sin embargo, se observan ligeras diferencias en función de la posición que ocupan los diferentes piezómetros, que una vez analizados ofrecen información interesante. Se diferencian dos grupos de piezómetros (Figuras 8 a y b, Tabla 2).

La evolución piezométrica identificada en los puntos de observación de la zona de estudio se ha dividido en cuatro fases que definen su comportamiento en el periodo comprendido entre diciembre de 1999 y febrero de 2016 (Tabla 2). A su vez, de cada grupo de piezómetros diferenciado (oriental y occidental), se ha obtenido estadísticamente una "curva tipo" a partir del patrón piezométrico seguido en cada una de las fases. Los gráficos incluidos en la tabla 2 representan la "evolución piezométrica tipo" de cada sector, junto con la del sector contrario en gris, para facilitar la identificación de las diferencias. Además, la fecha que marca el límite de las fases es diferente para cada grupo de piezómetros.

Los piezómetros del sector oriental se caracterizan por presentar una cota piezométrica más profunda, con valores que oscilan entre 20 y $60 \mathrm{~m}$ de profundidad y una tasa de variación total de alrededor de 30 metros. A nivel de fases se distinguen los siguientes comportamientos:

Fase 1: descenso piezométrico prolongado hasta diciembre de 2009.

Fase 2: se produce un fuerte ascenso piezométrico con pendiente elevada de forma continuada hasta febrero de 2012.

La recarga que se produce en esta fase se interpreta como procedente, en su mayoría, de la infiltración del agua de lluvia generada durante las intensas 
del Pozo Tejado, J. y Mejías Moreno, M., 2017. Los Ojos del Guadiana y del Gigüela: ... Boletín Geológico y Minero, 128 (4): $885-911$

precipitaciones de este periodo, directamente en la zona de estudio y en áreas próximas situadas aguas arriba. La respuesta es, en consecuencia, prácticamente inmediata, y la respuesta piezométrica presenta en el gráfico una pendiente elevada.

Fase 3: desde febrero de 2012 a septiembre de 2015 se produce un ascenso piezométrico moderado, cuyo máximo se produce en un intervalo de fechas muy variable, pasando a un último periodo de estabilidad. Se puede decir que a partir de febrero de 2015 la tendencia piezométrica pasa a ser ligeramente descendente.

El ascenso piezométrico moderado de esta fase, que se extiende hasta septiembre de 2015 en el sector oriental, más allá del último periodo húmedo que se sucedió en 2013 , se interpreta como influenciado por la recarga lateral profunda procedente del sector más oriental de la Llanura Manchega y las MASb limítrofes, que se transfiere hacia el oeste con cierto retardo temporal (comportamiento inercial del acuífero carbonatado Plioceno).

Fase 4: desde septiembre de 2015 la piezometría sigue una tendencia descendente de pendiente moderada.

El periodo seco 2014-2016 tiene como consecuencia el descenso de niveles piezométricos que, en la zona oriental, tiene una pendiente moderada.

Los piezómetros del sector occidental se caracterizan por presentar una cota piezométrica más somera, con valores que oscilan entre 5 y $40 \mathrm{~m}$ de profundidad y una tasa de variación total de alrededor de 20 metros. Las 4 fases de finidas presentan el siguiente patrón:

Fase 1: descenso piezométrico prolongado hasta diciembre de 2009.

Fase 2: se produce un brusco ascenso piezométrico con pendiente muy elevada consecuencias de las fuertes lluvias del invierno 2009-2010. Este ascenso se ve interrumpido por un periodo de rápido descenso piezométrico al que le sigue un nuevo periodo de brusco ascenso hasta enero de 2011, consecuencia, en este caso, del año hidrológico húmedo 2010/11.

La interrupción en la tendencia ascendente del invierno 2009-2010 y el notable descenso piezométrico durante el verano de 2010 constituye la diferencia clave con respecto al grupo oriental. La recarga, que en esta etapa se interpreta como procedente de la infiltración directa del agua de lluvia, produce un importante ascenso piezométrico durante el invierno de 2009-2010 e, inmediatamente, se torna en descenso en la etapa estival de 2010. La recarga local genera un ascenso piezométrico temporal durante la fase de lluvias, pero rápidamente vuelve a descender el nivel a medida que esta recarga directa se va despla- zando hacia los niveles acuíferos más profundos que no se encontraban saturados. La pendiente de las gráficas de ascenso y descenso es elevada, indicativo de una respuesta relativamente rápida a los eventos de precipitación e infiltración de agua hacia los niveles inferiores.

En el invierno de 2010 se vuelven a producir precipitaciones importantes que revierten la tendencia piezométrica descendente y generan un nuevo input de recarga, ahora en unas condiciones en que los niveles más profundos se encuentran saturados.

Fase 3: desde enero de 2012 a diciembre de 2015 se produce un ascenso piezométrico moderado, cuyo máximo se produce en un intervalo de fechas muy variable, pasando a un último periodo de estabilidad. Se puede decir que a partir de diciembre de 2015 la tendencia piezométrica pasa a ser descendente.

La pendiente de la gráfica de ascenso piezométrico es menor que en el mismo tramo de los piezómetros del sector oriental $y$, sin embargo, la duración de la tendencia ascendente es mayor, más alejada en el tiempo del último periodo húmedo del año 2013. Como ya se ha dicho antes, se interpreta que el ascenso piezométrico de esta fase está influenciado por la recarga lateral profunda procedente del sector oriental, que se desplaza en sentido oeste con cierto retardo.

En el caso de los piezómetros ubicados en el sector occidental, la recarga más inercial no se transmite de forma directa, sino que su llegada se ve retrasada en favor de los depocentros, en los que la cota piezométrica se sitúa por debajo de la cota de avance. En consecuencia, el ascenso piezométrico de esta fase es más lento y su duración mayor dado el retardo al que se ve sometido el avance del flujo.

Fase 4: desde diciembre de 2015 la piezometría general reflejada en los piezómetros del sector occidental muestra, al igual que en el sector oriental, una tendencia descendente, aunque de pendiente más suave.

El comportamiento piezométrico de esta fase no es coherente, a priori, con la surgencia de agua en los ojos del Gigüela. En este caso, la tendencia piezométrica está condicionada por la posición de los piezómetros integrantes de la red de seguimiento.

\section{Isopiezas del entorno de los ojos del Guadiana y los ojos del Gigüela}

El mapa de isopiezas de febrero de 2016 (Figura 9) en el entorno de los ojos muestra un flujo subterráneo de dirección este-oeste, acorde con la dirección del flujo en el sector central de la CAG desde el año 2012 
del Pozo Tejado, J. y Mejías Moreno, M., 2017. Los Ojos del Guadiana y del Gigüela: ... Boletín Geológico y Minero, 128 (4): $885-911$

(Figura 10), y similar a las condiciones hidrodinámicas naturales del acuífero.

Se describen dos divisorias de agua subterránea a escala local. Por un lado, la divisoria subterránea que delimita el flujo hacia el Guadiana y hacia el Gigüela $y$, por otro, la divisoria de agua a partir de la cual el flujo subterráneo toma dirección hacia el Guadiana o hacia los arroyos de las Morillas y Pellejero.

Las isopiezas reflejan inflexiones en la dirección del flujo subterráneo a favor de los principales cauces, aunque se distinguen tramos con diferentes relaciones río-acuífero: el río Gigüela presenta un carácter ganador por su margen izquierda en su curso desde Villarta de San Juan hasta el PNTD. A fecha de febrero de 2016 el antiguo cauce de este río continúa actuando de nivel de base hidrogeológico en el extremo más septentrional de la MASb Mancha Occidental I, a pesar de estar canalizado a su paso por Villarrubia de los Ojos.

En el río Guadiana se diferencian varios tramos de diferente relación río acuífero, a fecha de febrero de 2016 (Figura 9):

Aguas arriba de Los ojos del Guadiana, donde el cauce se denomina arroyo de la Madara, las isopiezas reflejan un régimen influente, con una dirección de flujo subterráneo divergente en direcciones noroeste y suroeste.

El tramo del río Guadiana comprendido entre su nacimiento (ojos más orientales) y la confluencia con el río Azuer presenta carácter ganador o efluente por su margen izquierda, y carácter perdedor o influente por su margen derecha. Hidráulicamente este escenario se traduce en que los ojos del Guadiana presentan agua en superficie en este tramo, pero la cota piezométrica no alcanza la suficiente altura como para producir un caudal circulante permanente.

Al oeste de la incorporación del río Azuer, el río Guadiana presenta régimen ganador o efluente por ambas márgenes hasta su entrada en el PNTD. Este tramo coincide con el sector del río que presenta caudal circulante permanente desde el año 2012 hasta el momento de elaboración de este artículo, mayo de 2016.

En relación a la posición de Los ojos del Guadiana y los ojos del Gigüela, en ambos casos los manantiales actualmente activos se sitúan en tramos del río ganadores, al menos por una de sus márgenes.

\section{Piezometría de las MASb centrales de la cuenca alta del río Guadiana}

La comparación de los mapas de isopiezas del sector central de la CAG refleja la evolución piezométrica en los últimos años (Figura 10). En la situación piezomé- trica del año 2010, las isopiezas describen una depresión en el sector central de la CAG, allí donde el acuífero terciario carbonatado alcanza su máxima potencia (depocentros de Villarta de San Juan, Daimiel y las Tablas). La depresión se origina a partir de la intensa explotación del acuífero a partir del comienzo de la década de los 80 del pasado siglo. El descenso piezométrico consecuente se hace más pronunciado allí donde la potencia del acuífero es mayor (depocentros sedimentarios).

La superficie piezométrica en el año 2010 y anteriores se situaba por debajo de la cota 600 m s.n.m., haciendo confluir el flujo subterráneo de la Llanura Manchega hacia el sector central. La dinámica hidrogeológica se encuentra totalmente modificada con respecto al estado natural, en el que el flujo subterráneo discurría de forma continua en sentido este-oeste.

A partir del año 2012 se restablece la circulación de agua subterránea en sentido natural, consecuencia del ascenso piezométrico generado a partir del periodo húmedo que comenzó en diciembre de 2009. A pesar del restablecimiento de la dirección de flujo general, la morfología de las isopiezas de los años posteriores (2013 a 2015) continúa mostrando direcciones de flujo concentradas hacia las áreas de mayor espesor del acuífero (depocentros sedimentarios). Este comportamiento sería indicativo de que los niveles profundos no saturados se están rellenando a favor de un gradiente piezométrico inferior. A la vez, se restablece la transferencia lateral de flujo hacia el oeste, consecuencia, en primer término, de la recarga superficial.

En el año 2016 las isopiezas reflejan un trazado más abierto en sentido este-oeste, ya no orientadas hacia los depocentros. Esto sería indicativo de la saturación de los niveles profundos y de que la circulación del agua subterránea presenta continuidad lateral uniforme hasta su zona de descarga, al oeste. En términos hidrogeológicos esto supone la mayor aproximación a las condiciones naturales del acuífero desde el año 1983 (Figura 10).

\section{Interpretación de los resultados}

\section{Los ojos del Guadiana}

La presencia de agua en los ojos se debe, como ya se ha dicho, a la intercepción de la cota piezométrica con la cota de la superficie topográfica. La piezometría está directamente relacionada con las condiciones climatológicas que determinan la recarga de los acuíferos y con el aprovechamiento de las aguas subterráneas.

En el piezómetro 1930.4.0040, del IGME, situado 


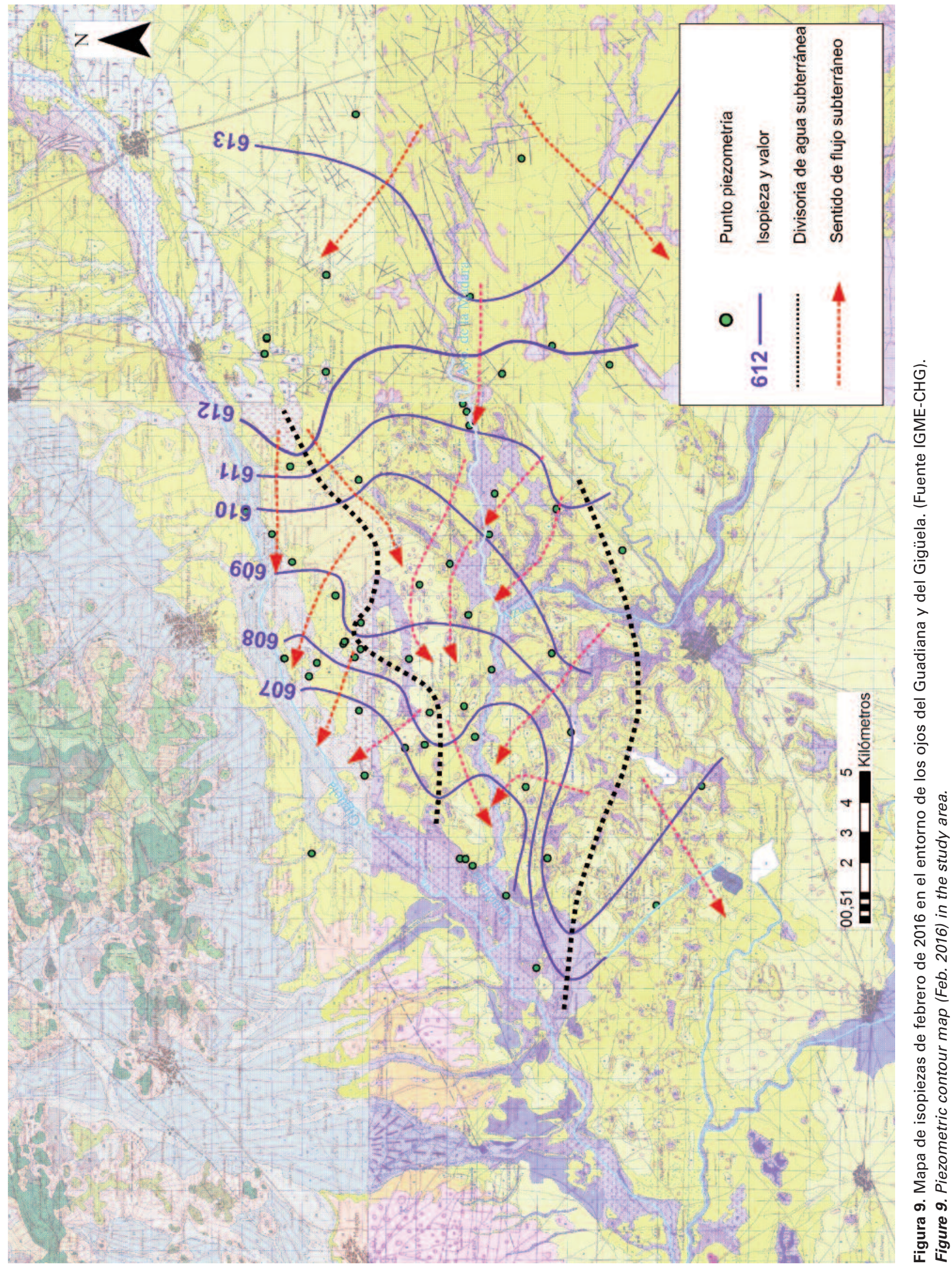



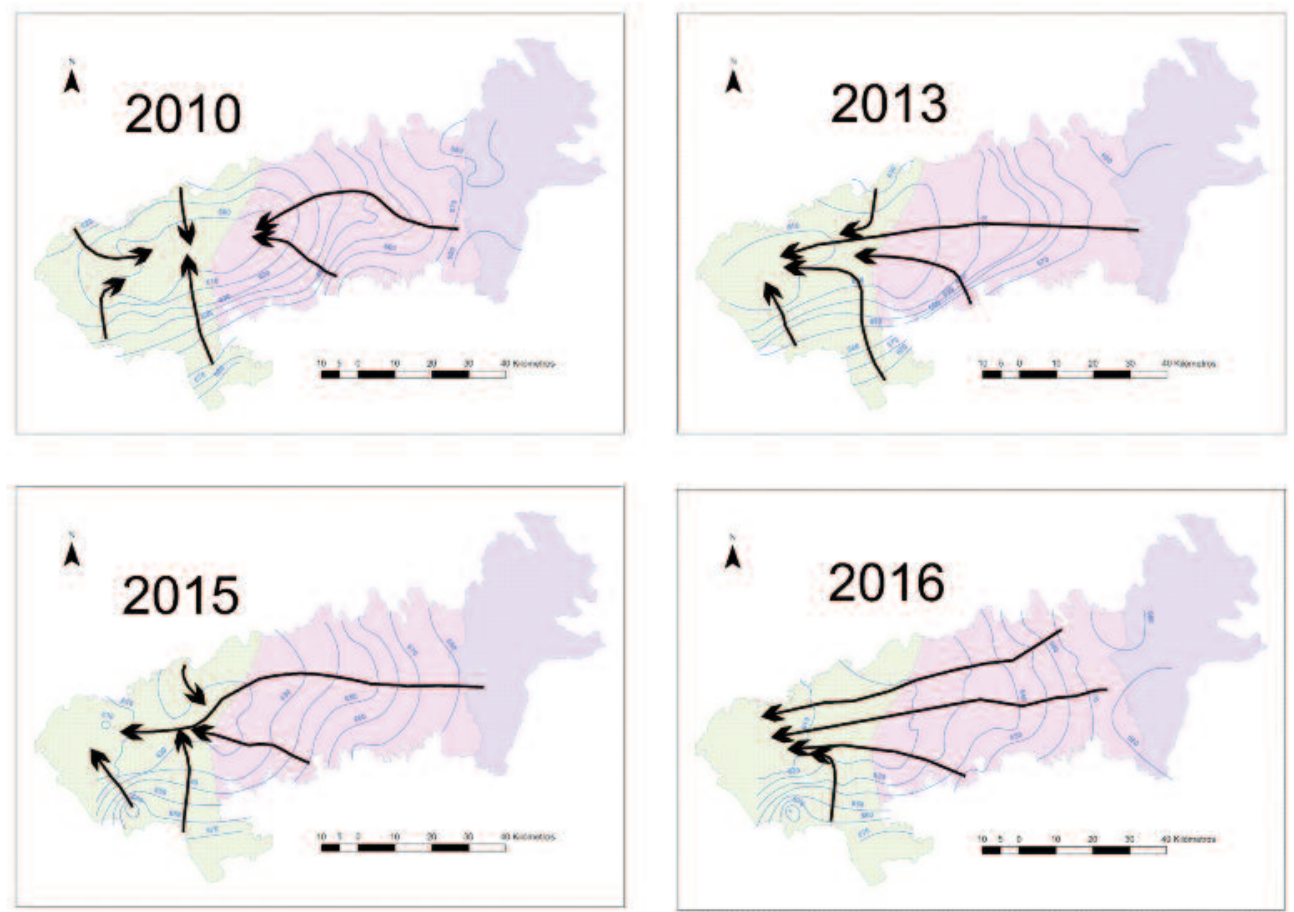

Figura 10. Mapas de isopiezas del sector central de la CAG que reflejan la evolución piezométrica en el periodo $2009-2016$.

Figure 10. Piezometric contour maps of the central sector of Upper Guadiana in 2009-2016.

en el entorno de Los ojos del Guadiana, se refleja la evolución piezométrica de la zona de surgencia. Las fechas con presencia de agua en los ojos corresponden a episodios en los que las condiciones meteorológicas y de explotación del acuífero permiten el ascenso de cota piezométrica hasta la de surgencia situada en 611-612 m s.n.m. (Figura 11).

Los mínimos piezométricos se producen al final de las secuencias secas. En la figura 11 se identifican dos mínimos piezométricos: uno primero, asociado al final del periodo de sequía 1978-1995, que produjo un descenso piezométrico en la zona de Los ojos del Guadiana de unos de $36 \mathrm{~m}$, y un segundo mínimo relativo a finales de 2009 tras el periodo seco 19992009, que supuso un descenso de unos $25 \mathrm{~m}$ con respecto a la condiciones existentes en el año 1980.

\section{Evolución piezométrica de los puntos de control}

La evolución piezométrica regional está condicionada por la recarga superficial y por la subterránea, además del factor meteorológico. Las extracciones juegan un papel importante en la evolución piezométri$\mathrm{ca}$, si bien no existen datos más allá del volumen de extracción anual establecido por la normativa vigente, como ya se ha comentado.
La recarga superficial se produce por infiltración de agua de lluvia, por infiltración de agua de los ríos y por retornos de riego. El reflejo en la piezometría tiene un efecto de ascenso inmediato, aunque el descenso sería igualmente rápido en un escenario climatológicamente seco. En las gráficas de evolución piezométrica de la figura 8 a, este tipo de recarga sería la responsable de la morfología serrada, en la que la magnitud de ascensos y descensos depende de la intensidad de las precipitaciones y de la duración de los periodos secos.

La recarga profunda se produce por transferencia lateral desde otros acuíferos, en este caso, básicamente, por conexión con la MASb Mancha Occidental II. Esta recarga tiene un efecto más retardado en el tiempo, por el efecto inercial de la circulación del agua en el acuífero (Mejías y del Pozo, 2015). Mediante esta vía, la recarga se haría de forma directa a los niveles más profundos del acuífero carbonatado Plioceno. En el gráfico de la figura 8 a, el efecto de este tipo de recarga estaría reflejado en la tendencia de ascenso piezométrico continuo que comienza en 2009, que alcanza su máximo en un periodo variable entre los años 2014 y 2015, y que en 2016 se encuentra en ligero descenso.

En el caso de Los ojos del Guadiana, el importante ascenso piezométrico que tiene lugar a partir del 


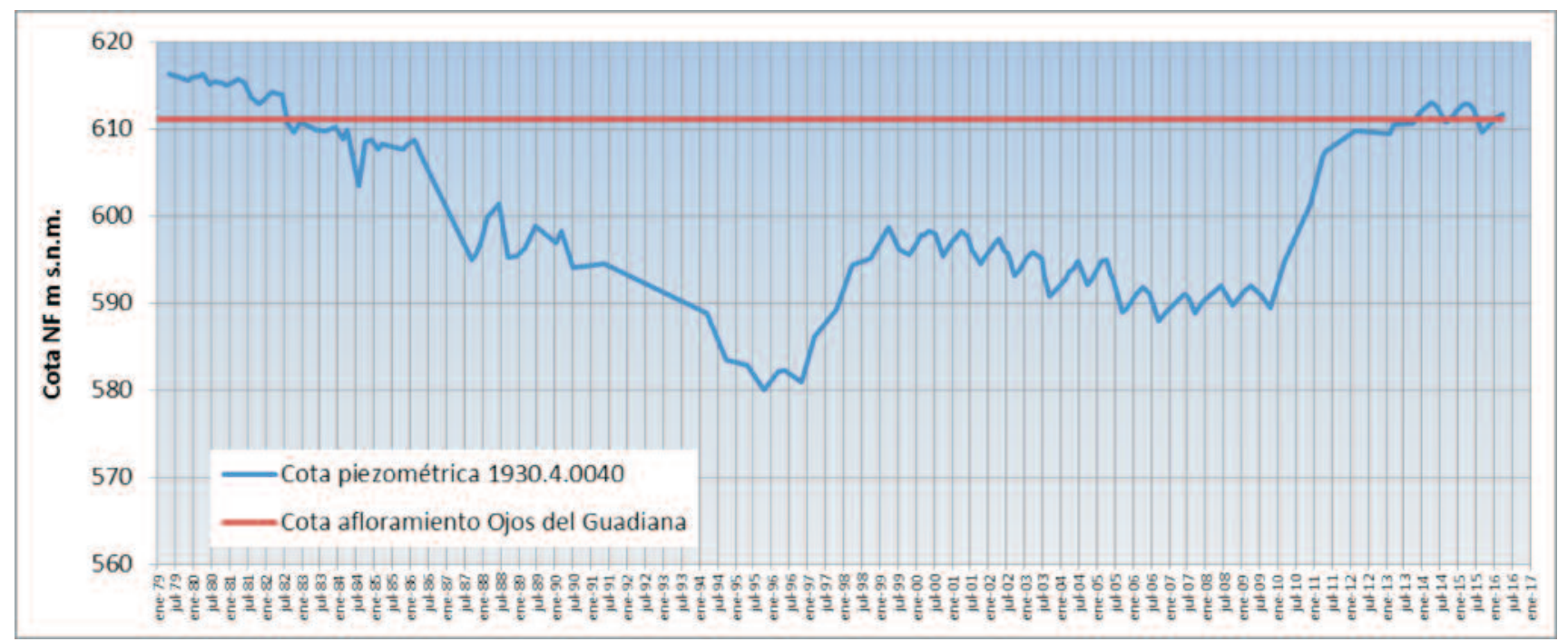

Figura 11. Gráfico de evolución piezométrica en el piezómetro IGME 1930.4.0040 (Mejías y del Pozo, 2016).

Figure 11. Piezometric evolution in IGME 1930.4.0040 (Mejías y del Pozo, 2016).

episodio de lluvias del invierno $2009-2010$ se produce a partir de una recarga directa en primera instancia (fuerte ascenso piezométrico a partir de diciembre de 2009) y posterior contribución de la recarga profunda que hace que se mantenga la tendencia ascendente hasta febrero de 2015, aunque de forma más moderada. En este periodo se produce el ascenso progresivo de nivel en el depocentro de Villarta de San Juan de manera que, una vez que la cota piezométrica rebasa la cota de afloramiento, se identifica la aparición de agua en Los ojos del Guadiana.

\section{Isopiezas locales de la zona de estudio}

El cruce de la información procedente de las isopiezas y direcciones de flujo local, con la información procedente de la morfología del acuífero carbonatado plioceno, permite identificar una importante relación entre las direcciones de flujo resultantes con la morfología de la base del acuífero, concretamente con la posición de los depocentros y umbrales sedimentarios (Figura 12). El avance del flujo subterráneo hacia su zona de descarga en los ojos del Guadiana, ojos del Gigüela y Tablas de Daimiel se ve condicionado por la posición de los diferentes umbrales y depocentros sedimentarios, siempre teniendo en cuenta un escenario de partida de mínimos piezométricos como el que tuvo lugar hasta diciembre de 2009.

Hacia el oeste, en el sentido de avance del flujo subterráneo hacia su zona de descarga natural, el muro de la unidad carbonatada asciende progresiva- mente adaptándose a la morfología del zócalo paleozoico, que llega a aflorar al oeste de las Tablas de Daimiel. Lateralmente también se produce una limitación paulatina de la sección del acuífero, al cerrarse la cubeta sedimentaria entre los afloramiento paleozoicos de los Montes de Toledo y de Campo de Calatrava. El agua se ve inducido a ascender en su sentido de avance, a través de una sección de acuífero progresivamente menor. Este aspecto se refleja en las isopiezas en forma de incremento de gradiente piezométrico entre los sectores oriental y occidental de Los Ojos del Guadiana. La superficie piezométrica se sitúa progresivamente más cercana a la superficie, como así corrobora el incremento sustancial de las estructuras de disolución kárstica superficiales al oeste de Los Ojos del Guadiana (Bórnez et al. 2017).

Ante la reducción de potencia de la unidad carbonatada pliocena cobran relevancia las irregularidades en la base de la misma. Especialmente relevante resulta la presencia del umbral de Los Ojos del Guadiana para la génesis de los manantiales homónimos. La interposición del umbral sedimentario en el sentido de avance del flujo contribuye, por un lado, a incrementar el ascenso piezométrico inducido que ya se venía dando y, por otro lado, dado que la reducción de sección de acuífero es considerable comparada con el gran volumen de agua que circula en este sentido, el flujo modificaría su dirección de avance alrededor del umbral, hacia zonas de mayor potencia de acuífero, siempre y cuando los límites espaciales lo permitan.

En función de estas direcciones hacia los flancos 


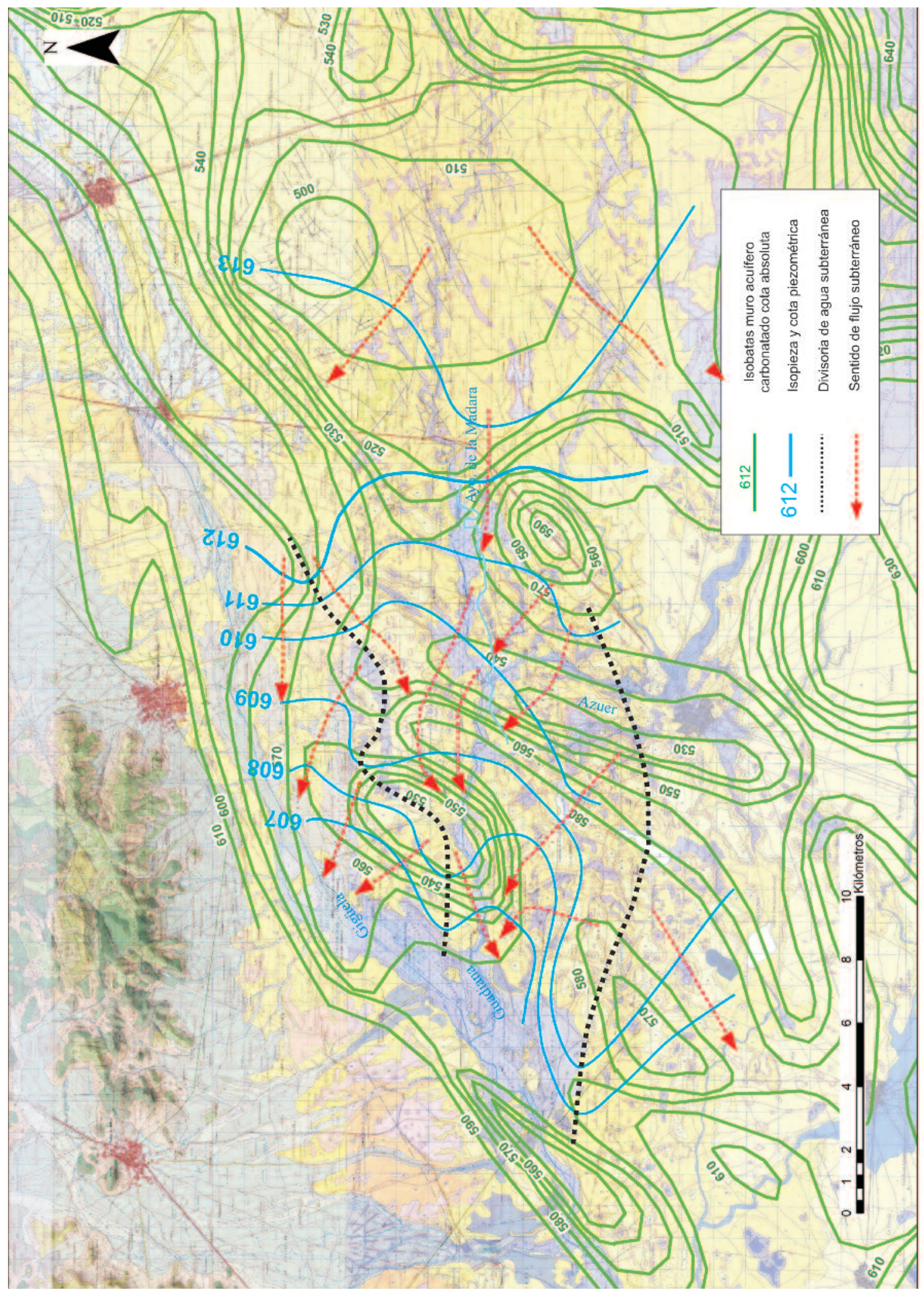

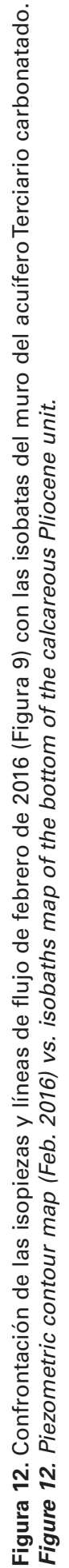




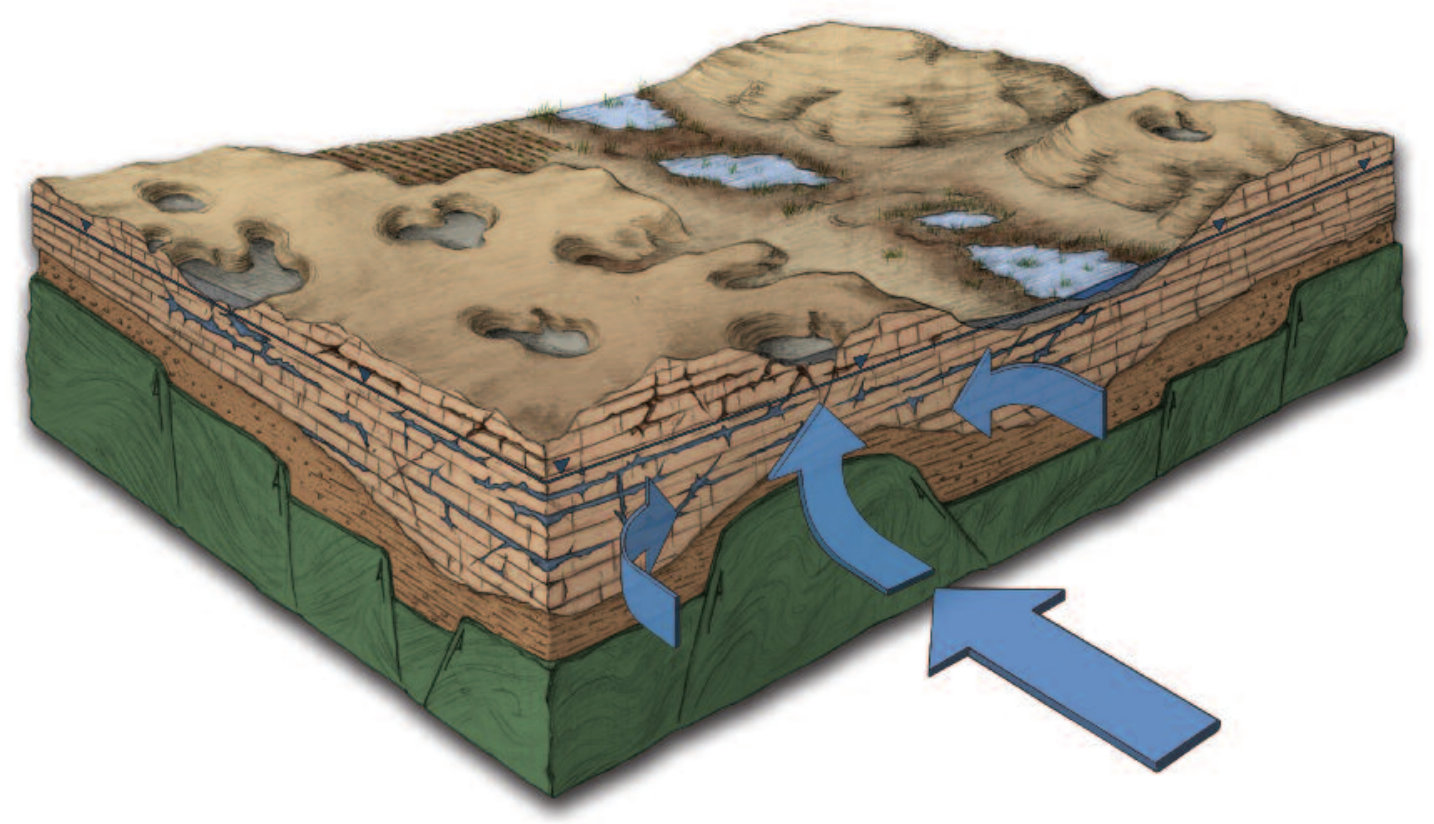

Figura 13. Modelo conceptual interpretativo del marco geotectónico que induce a la formación de los Ojos del Guadiana (Ilustración M. Rajado).

Figure 13. Conceptual model of the origin of the Ojos del Guadiana springs (Picture: M. Rajado).

norte y sur del umbral, se da la circunstancia de que hacia el sur el acuífero no tiene una limitación cercana a su extensión, mientras que en sentido norte los materiales impermeables del zócalo afloran a escasos $10 \mathrm{~km}$ (límite del surco manchego con los afloramientos paleozoicos de los Montes deToledo) por lo que la limitación espacial del acuífero es más acusada si cabe.

Tanto la limitación en la potencia de acuífero, como la limitación espacial lateral determinan que en Los Ojos del Guadiana se den unas condiciones especialmente favorables a los procesos de disolución kárstica y ascenso de nivel piezométrico. Así, el tramo de río en el que se sitúan Los Ojos del Guadiana, geomorfológicamente, respondería a una concatenación de depresiones kársticas de tipo dolina, en el fondo de las cuales se ubican Los Ojos del Guadiana, tal y como ya se apunta en García, 1996. El flujo subterráneo que circunda el umbral de Los Ojos del Guadiana por el norte encuentra una vía de drenaje preferente a favor de la karstificación inducida, hecho que convierte a estos manantiales en uno de los puntos más importante de drenaje de la CAG, en condiciones naturales unos $90 \mathrm{Hm}^{3} /$ año de media (Figura 13).

\section{Surgencia de agua en los ojos del Gigüela}

En el entorno inmediato de los ojos del Gigüela no existe ningún punto de control que tenga seguimiento piezométrico con periodicidad suficiente de medida, ni datos históricos para fijar con precisión la cota piezométrica de la surgencia. A tenor del afloramiento de agua en diciembre de 2016, los ojos del Gigüela presentan agua en superficie cuando la cota piezométrica local alcanza la cota absoluta de 607-608 m s.n.m. (Mejías y del Pozo, 2016).

La reconstrucción del avance del flujo subterráneo hacia su extremo occidental de descarga (al oeste de Los ojos del Guadiana) sigue una trayectoria condicionada por la morfología del muro del acuífero mencionada anteriormente, e impuesta por el escenario de mínimos piezométricos ya referido.

En ausencia de piezómetros pertenecientes a la red de observación de la CHG o del IGME en zonas específicas de los depocentros y umbrales, la hipótesis planteada se basa en una reconstrucción del avance de flujo subterráneo condicionado por la existencia de gradientes hidráulicos puntuales. En este sentido, cabría incidir en que el avance del flujo no se produciría en los mismos términos espacio-temporales si el escenario de partida fuera de mínimos piezométricos, o si por el contrario el escenario de partida corresponde a un escenario piezométrico diferente.

Una vez que la recarga lateral procedente del sector oriental, y el consecuente ascenso piezométrico, alcanza la cota de drenaje en Los Ojos del Guadiana (fase A, Figura 14), el flujo subterráneo se transmite 


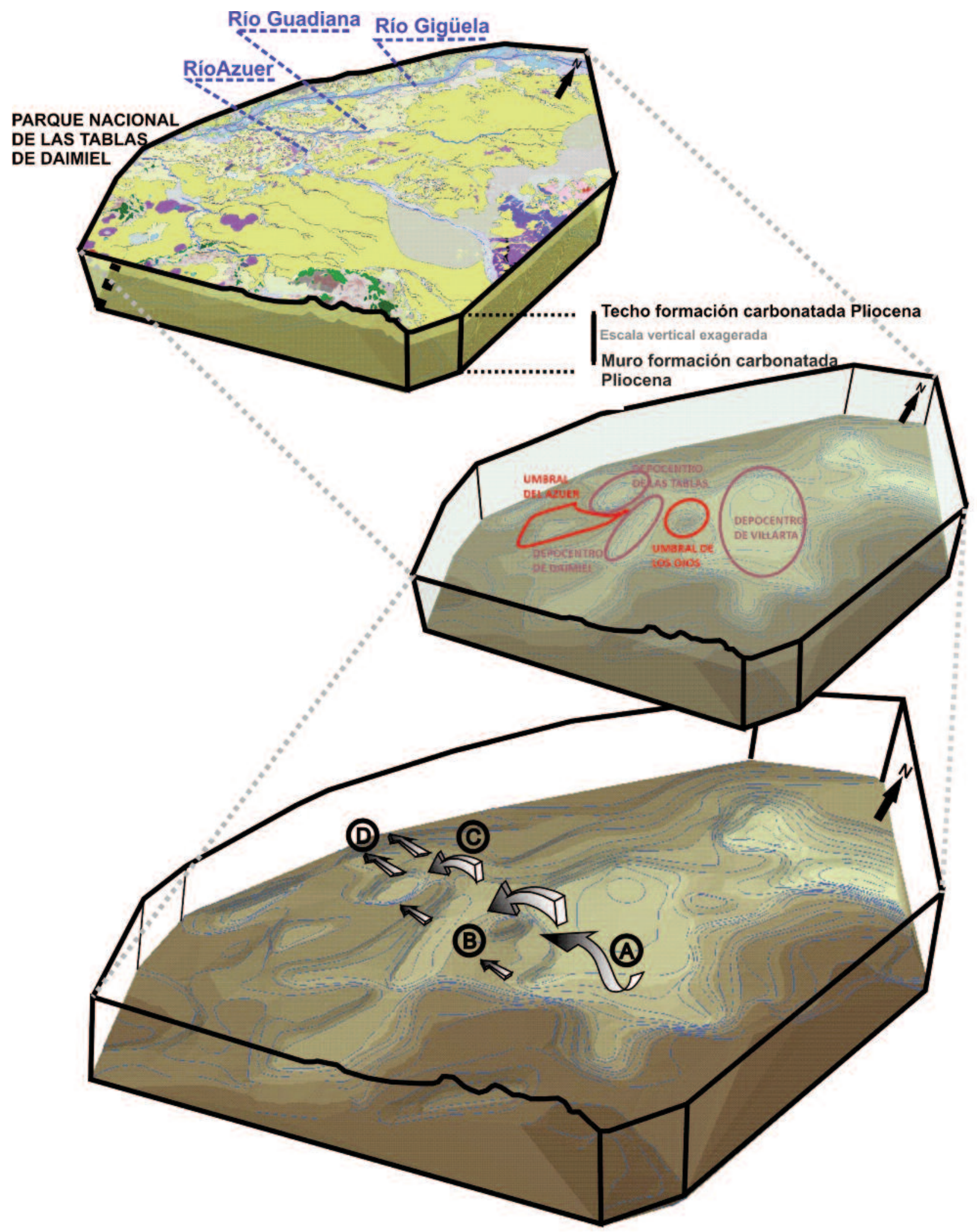

Figura 14. Modelo 3D de interpretación de las fases de avance del flujo subterráneo en función de la morfología del acuífero terciario carbonatado, en un escenario de partida de "vacío piezométrico relativo" (Bloques-diagrama: N. García).

Figure 14. 3D interpretative model for the evolution of the subterranean recharge in the Pliocene calcareous unit in a minimum piezometric state. (diagrams: N. García). 


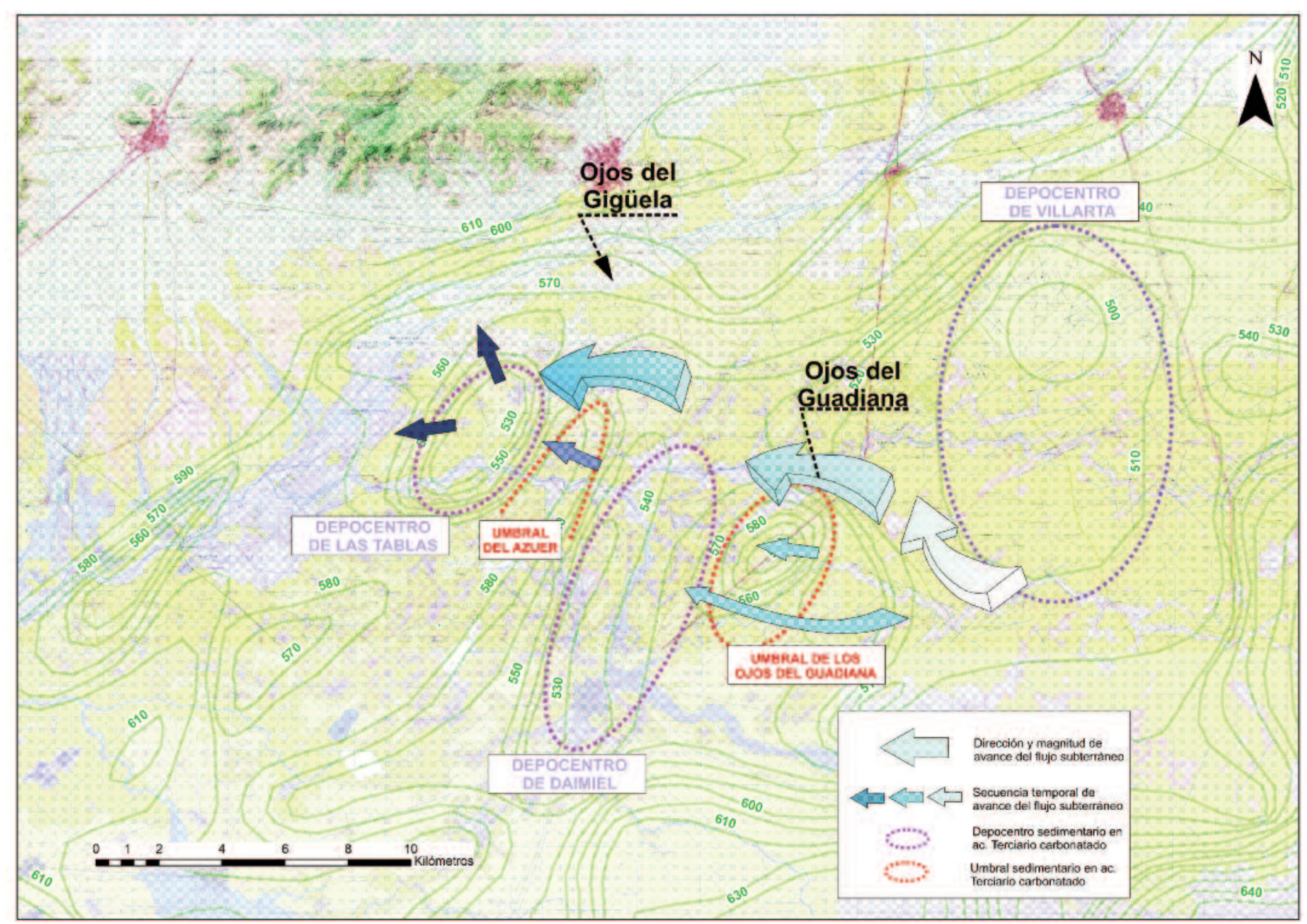

Figura 15. Interpretación de las fases de avance del flujo subterráneo en función de la morfología del acuífero terciario carbonatado, es un escenario de partida de "vacío piezométrico relativo". (Elaboración propia).

Figure 15. Interpretation of the evolution of subterranean recharge for the Pliocene calcareous unit in a minimum piezometric state.

hacia el oeste generando un ascenso piezométrico progresivo en este sentido (fase B, Figura 14). En este camino, se interpone el depocentro de Daimiel que, en el sentido de avance $y$, ante un escenario de mínimos piezométricos, hace que el flujo subterráneo se dirija preferentemente a ocupar los niveles no saturados más profundos del acuífero, antes de dar continuidad lateral a su avance hacia el oeste.

A continuación, una vez que el ascenso piezométrico ya se ha hecho efectivo en la vertical del depocentro, la transferencia de flujo lateral continúa su camino hacia el oeste, encontrándose en esta dirección con un umbral sedimentario (umbral del Azuer), que derivaría parcialmente el flujo subterráneo hacia su flanco septentrional en donde el acuífero Plioceno tiene una potencia mayor (fase C, Figura 14). En términos de avance de flujo subterráneo, el efecto de este umbral sería una nueva alteración en la direc- ción, que no se produciría de no existir estas singularidades del basamento.

Inmediatamente después de este umbral, se dispone un nuevo depocentro (depocentro de Las Tablas), que actuaría de nuevo a modo de "sumidero" piezométrico (se reitera de nuevo la situación de mínimos piezométricos), redirigiendo el flujo subterráneo hacia los niveles no saturados más profundos del acuífero a favor del gradiente hidráulico.

Una vez que la cota piezométrica asciende en la vertical de este último depocentro, la continuidad del flujo subterráneo ya podría seguir hacia las zonas de descarga de los ojos del Gigüela, al norte del depocentro, y hacia las Tablas de Daimiel, al oeste (fase D, Figura 14).

Esta es la situación que se estaría produciendo a fecha de febrero de 2016: el avance del flujo subterráneo que refleja el ascenso piezométrico consecuencia 
del Pozo Tejado, J. y Mejías Moreno, M., 2017. Los Ojos del Guadiana y del Gigüela: ... Boletín Geológico y Minero, 128 (4): $885-911$

del periodo húmedo 2009-2013 alcanza su extremo más occidental de descarga correspondiente a los ojos del Gigüela y las Tablas de Daimiel. El proceso de recarga del acuífero por transferencia lateral sería la razón del desfase temporal en la surgencia de agua en Los ojos del Guadiana (enero de 2012) y los del Gigüela (diciembre de 2015), pese a estar separados únicamente por $7 \mathrm{~km}$ de distancia (Figura 15).

\section{Conclusiones}

En los últimos años se viene especulando sobre la posibilidad de que un periodo de elevadas precipitaciones, como el acontecido entre los años 2009 a 2013, haya sido capaz de generar una recarga suficiente como para provocar una recuperación del acuífero hasta alcanzar valores piezométricos similares a los de la década de los 80 del siglo XX, situación considerada como "natural" $\mathrm{O}$, al menos, en la que se mantienen las condiciones naturales del flujo subterráneo. Los resultados expuestos en este trabajo analizan esta evolución y avanzan en la mejora del conocimiento de la recuperación hidrogeológica experimentada en la MASb Mancha Occidental I en el periodo 2009-2016.

Es la primera vez que se queda registrada la recuperación de la surgencia de agua en los ojos del Guadiana y del Gigüela desde que se hace un seguimiento sistemático de los niveles piezométricos (año 1973). El periodo húmedo 2009-2013 generó un importante ascenso piezométrico que se tradujo en el ascenso de niveles generalizado en la cuenca alta del Guadiana hasta alcanzar cotas similares a las de los primeros años de la década de los 80 del pasado siglo. A raíz de esta recuperación hidrológica, Los ojos del Guadiana se reactivan en el año 2012, y la dirección regional de flujo subterráneo retorna a su dinámica natural en sentido este-oeste en este mismo año. Los ojos del Gigüela se recuperan 4 años después, en pleno periodo seco 2014-2016.

La piezometría regional de la zona de estudio, a fecha de 2016, muestra una relación río -acuífero efluente o ganadora en aquellos tramos que presentan agua en superficie: únicamente por uno de sus márgenes en el caso de encharcamientos dispersos; y por ambos márgenes en los tramos con flujo de agua circulante.

La evolución de las isopiezas de la Llanura Manchega refleja un proceso en el que, a partir de 2012, año en el que se restablece la dirección de flujo natural, la fluencia hacia el oeste se hace progresivamente más nítida hasta el año 2016. En este periodo, el flujo pasa de dirigirse hacia la zona central de la
MASb Mancha Occidental I a dirigirse de forma neta hacia la zona de descarga occidental.

La morfología del acuífero Plioceno carbonatado resulta determinante en esta evolución, tanto en su forma como en sus tiempos. Puesto que la superficie topográfica es eminentemente plana, cobra importancia la morfología de la base del acuífero, especialmente a medida que se reducen las dimensiones de este (sección de paso). Se han identificado la existencia de irregularidades, como umbrales y depocentros sedimentarios.

Existe un comportamiento piezométrico diferenciado al este y al oeste de la posición del umbral de Los Ojos del Guadiana. En el sector oriental la recarga profunda llega directamente en forma de ascenso piezométrico progresivo. En el sector occidental (ojos del Gigüela) la recarga se ve retardada en el tiempo en favor de los niveles más profundos del acuífero, no saturados en gran parte, cuando se inicia el periodo húmedo 2009-2013 (depocentros sedimentarios).

En el sentido de avance del flujo subterráneo, desde el depocentro de Villarta, el agua se ve obligado a ascender a medida que se reduce la sección de paso del acuífero por proximidad de sus límites inferior y laterales. Se crea de este modo una componente de flujo vertical que favorece los procesos de disolución en la serie pliocena carbonatada.

El agua subterránea tiene, consecuentemente, mayor influencia en la superficie del terreno. Se evidencia un incremento significativo de estructuras de disolución (dolinas y uvalas) al oeste del umbral de Los Ojos del Guadiana.

Este umbral condiciona la existencia, posición y morfología de Los ojos del Guadiana. La reducción de sección de paso y redireccionamiento del flujo favorecen los procesos de karstificación hacia el flanco norte del umbral de Los Ojos del Guadiana. En consecuencia, este grupo de manantiales se sitúa en el cauce formado a partir de la sucesión de estructuras de disolución kárstica de tipo dolina.

El escenario hidrogeológico de mínimos piezométricos resulta clave para la proposición de la hipótesis que explica el desfase temporal entre la surgencia de agua en Los ojos del Guadiana y del Gigüela: la sucesión de varios depocentros en el sentido de avance determina la existencia de gradientes piezométricos que desvían, temporalmente, el flujo subterráneo hasta saturar los niveles más profundos. Los umbrales sedimentarios, por su parte, favorecen determinadas direcciones de flujo hacia zonas de mayor potencia del acuífero.

En definitiva, el periodo húmedo 2009-2016 ha registrado un proceso de recuperación hidrogeológica muy importante en las MASb centrales de la cuenca alta del Guadiana: 
del Pozo Tejado, J. y Mejías Moreno, M., 2017. Los Ojos del Guadiana y del Gigüela: ... Boletín Geológico y Minero, 128 (4): $885-911$

Los niveles piezométricos han ascendido hasta niveles que no se daban desde el comienzo de la década de los 80 del pasado siglo.

La circulación de agua subterránea en dirección este-oeste se restablece en 2012 y se mantiene hasta la fecha de elaboración de este artículo. Las isopiezas anuales reflejan una tendencia hacia direccional que tiende a aproximarse al estado natural $y$, por el momento, no se ha visto alterada por el descenso piezométrico ligado al último ciclo seco 2014-2016.

Los caudales de drenaje en régimen no alterado de estos manantiales y la superficie inundada asimilable a condiciones naturales están aún lejos de suceder. Además, el último periodo seco 2014-2016 ha comenzado a revertir el proceso de recuperación, iniciándose una ligera tendencia descendente.

\section{Discusión}

La hipótesis de circulación hidráulica expuesta en este artículo se basa en el hecho empírico de la recuperación de la surgencia de agua en los ojos del Guadiana y del Gigüela, en fecha y en periodos climatológicos diferentes. Por otro lado, el cruce de información hidrogeológica reciente con la tectónica y la morfología de los cuerpos sedimentarios y el zócalo de la zona ha posibilitado el establecimiento de una hipótesis coherente y totalmente factible con los datos actuales, en un escenario piezométrico de partida de mínimos piezométricos relativos, seguido de un periodo de recuperación que acerca las condiciones hidrogeológicas de febrero de 2016 a las del estado natural.

En la línea de confirmación de la hipótesis plateada sería recomendable la ejecución de una serie de trabajos que a continuación se relacionan brevemente:

Completar la red de observación piezométrica. Existen zonas en las que las redes de observación piezométrica del IGME y de la CHG no cuentan con información hidrogeológica suficiente. Se requiere un seguimiento piezométrico, de periodicidad mínima mensual, en los depocentros y umbrales sedimentarios citados en este informe. A modo de ejemplo, cabe citar que un hipotético piezómetro de control situado en el entorno de los ojos del Gigüela estaría registrando en 2016 los máximos piezométricos correspondientes al periodo húmedo 2009-2013, a diferencia del resto de piezómetros de la Llanura Manchega en los que este máximo ya ha sido alcanzado.

Replanteamiento del balance hídrico en la MASb Mancha Occidental I y sus implicaciones en la gestión hidráulica, una vez identificado el efecto de recuperación parcial del acuífero Plioceno en relación al periodo húmedo 2009-2013.

\section{Referencias}

Alonso-Gavilán, G., Armenteros, I., Carballeira, A., Huerta, P. y Rodríguez, J.M., 2004. Cuencas cenozoicas del Macizo Ibérico. En: Vera, J.A. (ed.), Geología de España. SGEIGME, Madrid, 581-586.

Álvarez-Cobelas, M., Cirujano, S. y Sánchez-Carrillo, S. (2001). Hydrological and botanical man-made changes in the Spanish wetland of Las Tablas de Daimiel. Biological Conservation, 97, 89-98.

Antón, J.A., 1975. Investigación geoeléctrica de la Llanura Manchega. Sistema 23. Informe inédito. Centro de documentación IGME, Madrid. 25 págs., 16 planos.

BOE $n^{\circ} 200,1956$. Ley de 17 de julio de 1956 sobre saneamiento y colonización de terrenos pantanosos que se extienden inmediatos a los márgenes de los ríos Guadiana, Cigüela, Záncara y afluentes de estos dos últimos en las provincias de Ciudad Real, Toledo y Cuenca.

Bórnez, K., Mejías, M., Camuñas, C., del Pozo, J. y del Moral, A., 2017. Inventario, clasificación y génesis de los colapsos del terreno en la Masa de Agua Subterránea Mancha Occidental I. Boletín Geológico y Minero, 128 (1): 43-68

CGS-INTECSA, 1975. Proyecto de investigación hidrogeológica de la cuenca alta y media del Guadiana, IGME. Informe inédito. Centro de documentación IGME, Madrid. 129 págs., 156 págs. gráficos y tablas, 13 planos.

García Rodríguez, M., 1996. Hidrogeología de las Tablas de Daimiel y de los Ojos del Guadiana. Bases hidrogeológicas para una clasificación funcional de humedales ribereños. Tesis doctoral. Universidad Complutense de Madrid, 438 págs., 4 Anejos.

Hernández-Pacheco, E. (1932). Síntesis fisiográfica y geológica de España. Trabajos del Museo Nacional de Ciencias Naturales de Madrid-Serie Geológica, 38, 584 pp.

IGN. Plan Nacional de Ortofotografía Aérea PNOA, 2006.

IGME, 2010. Encomienda de gestión para la realización de trabajos científico-técnicos de apoyo a la sostenibilidad y protección de las aguas subterráneas. Actividad 4: Identificación y caracterización de la interrelación que se presenta entre aguas subterráneas, cursos fluviales, descargas por manantiales, zonas húmedas y otros ecosistemas naturales de especial interés hídrico. Demarcación Hidrográfica 040 Guadiana. Masa de agua subterránea 040.007 Mancha Occidental I. 56 pp.

IGME, 1988. Hoja $n^{\circ} 760$ Daimiel. Mapa geológico de España, serie MAGNA 1:50.000.

IGME, 2013. Hoja $n^{\circ} 737$ Villarrubia de los Ojos. Mapa geológico de España, serie MAGNA 1:50.000.

ITGE, 1989. Sistema acuífero $n^{\circ}$ 23. Mancha Occidental. Serie: manuales de utilización de acuíferos.

Jerez, O., 2011. El poblamiento humano, en la reserva de la 
biosfera de la Mancha Húmeda. Jornadas ibéricas reservas de la Biosfera. UCLM.

López-Gutiérrez, J., Plata J.L. y Mejías, M., 2013. Caracterización de la divisoria hidrogeológica Guadiana-Júcar en la Llanura Manchega mediante técnicas geológicas geofísicas. Boletín Geológico y Minero. 124 (3) 381-404.

Martínez-Cortina, L. Mejías, M., Díaz, J.A., Morales, R. y Ruíz, J.M., 2011. Cuantificación de recursos hídricos subterráneos en la cuenca alta del Guadiana. Consideraciones respecto a las definiciones de recursos renovables y disponibles. Boletín Geológico y Minero, 122 (1): 17-36.

Mejías, M., 2012. Informe sobre evolución piezométrica de la unidad hidrogeológica 04.04 Mancha Occidental, en el periodo marzo 1980-enero 2012, y valoración de los encharcamientos de agua aparecidos en el entorno de Los Ojos del río Guadiana. Informe para la Confederación Hidrográfica del Guadiana, inédito.

Mejías, M., 2014. El agua protagonista a través de los siglos. En: Mejías, M. (ed.). Las Tablas y Los Ojos del Guadiana: agua, paisaje y gente. IGME-OAPN, Madrid: 15-64.

Mejías, M., López-Gutiérrez, J. y Martínez-Cortina, L., 2012. Características hidrogeológicas y evolución piezométrica de la Mancha Occidental. Influencia del periodo húmedo 2009-2011. Boletín Geológico y Minero, 123 (2): 91-108.

Mejías, M. y del Pozo, J. 2015. Informe sobre evolución piezométrica de las unidades hidrogeológicas declaradas sobreexplotadas incluidas en el ámbito del sistema de explotación oriental: 04.04, Mancha Occidental y 04.06, Campo de Montiel. Año 2015. Informe para la Confederación Hidrográfica del Guadiana, 16 pp.

Mejías, M. y del Pozo, J. 2016. Estudio hidrogeológico sobre el origen del agua aflorante en los ojos del río Gigüela, Villarrubia de los Ojos (Ciudad Real). Informe inédito, 53 pp.

Pérez González, A., 1981. Neógeno y Cuaternario de la Llanura Manchega y sus relaciones con la cuenca del Tajo. Tesis doctoral Ed. Univ. Complutense de Madrid. $787 \mathrm{pp}$.

SGOP 1979. Sobre la influencia en Las Tablas de Daimiel de la extracción de aguas subterráneas en la Llanura Manchega. Informe 11/79. Dirección General de Obras Hidráulicas, Ministerio de Obras Públicas y Urbanismo. 60 pp., anejos y planos.

TRAGSATEC, 2010. Informe final de los sondeos de captación y ensayos de bombeo ejecutados en las fincas de "la Duquesa" y "los Obregones" (Parque Nacional de las Tablas de Daimiel). 201 págs. + 76 págs. Anexos.

Recibido: junio 2016

Revisado: noviembre 2016

Aceptado: abril 2017

Publicado: diciembre 2017 